\title{
Synthesis, Characterization and in vitro Anticancer Activity of Novel 8,4'-Oxyneolignan Analogues
}

\author{
Gisele C. Souza, ${ }^{a}$ Gilberto C. Franchi Jr., ${ }^{b}$ Alexandre E. Nowill, ${ }^{b}$ Lourivaldo S. Santos, ${ }^{c}$ \\ Cláudio N. Alves, ${ }^{c}$ Lauro E. S. Barata ${ }^{d}$ and Carlos K. Z. Andrade ${ }^{*, a}$ \\ ${ }^{a}$ Laboratório de Química Metodológica e Orgânica Sintética, Instituto de Química, \\ Universidade de Brasília, 70910-900 Brasília-DF, Brazil \\ ${ }^{b}$ Centro Integrado de Pesquisas Oncohematológicas da Infância, \\ Universidade Estadual de Campinas, 13083-872 Campinas-SP, Brazil \\ 'Instituto de Ciências Exatas e Naturais, Universidade Federal do Pará, 66075-110 Belém-PA, Brazil \\ ${ }^{d}$ Laboratório de Sintese Orgânica, Universidade Estadual de Campinas, 13083-872 Campinas-SP, Brazil
}

\begin{abstract}
Neolignans are a class of natural products with a wide range of biological effects. These substances are of great synthetic and biological interest, especially in searching for novel anticancer agents. In this paper, we report the synthesis of a new subclass of 8,4'-oxyneolignan analogues ( $\beta$-ketoethers and $\beta$-ketoesters) and their cell viability assay on twenty four different cancer cells, among leukemias and carcinomas. Three compounds inhibited the growth of most human cancer cells. 2-Oxo-2-phenylethyl(2E)-3-[4-(2-oxo-2-phenylethoxy) phenyl]prop-2-enoate showed an antiproliferative activity superior to doxorubicin for U-87, U-138 MG and H1299 cell types and (E)-2-oxo-2-phenylethyl 3-(3-methoxy-4-(2-oxo-2-phenylethoxy)phenyl)acrylate was found to be very selective, demonstrating a growth inhibition of $92.0 \%$ against KG-1 cells. Furthermore, 1-oxo-1-phenylpropan-2-yl cinnamate exhibited significant inhibition activity in a range of 52.2 to 91.2\% against twelve kinds of leukemia cell lines, revealing excellent results and very comparable to the reference drug.
\end{abstract}

Keywords: neolignans, antiproliferative activity, MTT assay, $\beta$-ketoester, $\beta$-ketoether

\section{Introduction}

Cancer is a generic term for a large group of diseases that can affect any part of the body and remains a leading cause of death worldwide. It is considered a public health problem according to the World Health Organization, and many efforts have been made towards its prevention and cure. Treatment usually involves a series of interventions, and approximately $90 \%$ of tumors can be treated with antiblastic drugs,,${ }^{1,2}$ which makes chemotherapy the most used treatment. However, these drugs are non-selective and are toxic to healthy tissues, especially those of rapid cell proliferation..$^{2-5}$ As a consequence, there is an urgent need for novel and effective drugs that act against cancer.

Several substances have been thoroughly studied for their biological activities and a very promising class are the neolignans, which are substances derived from the oxidative

*e-mail: ckleber@unb.br coupling of allyl and/or propenyl phenols and are normally found in plants of the Myristicacea family. ${ }^{6-8}$ Neolignans have a wide range of biological effects such as antioxidant, ${ }^{9-14}$ antibacterial, ${ }^{15-17}$ anti-inflammatory, ${ }^{12,18-21}$ antifungal, ${ }^{22,23}$ anti-leishmanial, ${ }^{24-28}$ anti-trypanosomastid, ${ }^{27,28}$ and anticancer activity, ${ }^{13,14,29,30}$ among others. ${ }^{31-34}$ Therefore, this type of natural product is of great synthetic and biological interest, especially in searching for novel anticancer agents. In this paper, we report the synthesis of new 8,4 '-oxyneolignan analogues and the cell viability assays for different neoplasms, among leukemias and carcinomas.

\section{Experimental}

Chemistry

All reagents were purchased from commercial suppliers and were used as received, unless otherwise specified. Reactions were monitored by thin layer chromatography 
(TLC) using aluminum plates from Merck (silica gel $60 \mathrm{~F}_{254}$ ). Melting points (mp) were determined using a PFM II apparatus (model 382). Proton $\left({ }^{1} \mathrm{H}\right)$ and carbon $\left({ }^{13} \mathrm{C}\right)$ nuclear magnetic resonance (NMR) spectra were recorded on the following spectrometers: Bruker AC 250/P, Varian Mercury Plus $300 \mathrm{MHz}$, Bruker Avance $600 \mathrm{MHz}$ or Varian Inova $500 \mathrm{MHz}$. Chemical shifts are reported in ppm $(\delta)$ with values relative to TMS used as internal standard. High-resolution mass spectra (HRMS) were recorded on a VG AutoSpec High Resolution Mass Spectrometer (Micromass Company) or on a triple TOF 5600+ High Resolution Mass Spectrometer (AB Sciex) with internal calibration and direct solution (1 ppm in methanol).

General procedure for the synthesis of $8,4^{\prime}$-oxyneolignan analogues: $\beta$-ketoesters and $\beta$-ketoethers

A solution of 1.02 equivalent of phenols (or 0.51 equivalent of cinnamic acid derivatives) and 1.80 equivalent of anhydrous $\mathrm{K}_{2} \mathrm{CO}_{3}$ in anhydrous butanone (4.5 $\mathrm{mL}$ of solvent per mmol of phenol or cinnamic acid derivative) was stirred for $15 \mathrm{~min}$ at room temperature. After this period, a solution of 1.00 equivalent of $\alpha$-bromoketone in anhydrous butanone $(1.5 \mathrm{~mL}$ of solvent per mmol of ketone) was added dropwise and the mixture was stirred under reflux for $24 \mathrm{~h}$. The solution was cooled to room temperature, filtered, and the residue washed with $\mathrm{CHCl}_{3}$. The solution was concentrated in vacuum (to remove butanone), diluted with $\mathrm{H}_{2} \mathrm{O}$, and extracted with $\mathrm{CHCl}_{3}(3 \times)$. The organic extracts were combined, washed with water, $5 \% \mathrm{NaOH}$ solution, brine, dried over $\mathrm{Na}_{2} \mathrm{SO}_{4}$ and then filtered and concentrated in vacuum. The reaction products were purified by crystallization or column chromatography.

\section{2-(4-Nitro-phenoxy)-1-phenyl-ethanone (3a)}

Obtained according to the general procedure from $1.50 \mathrm{~g}$ (10.76 mmol) of 4-nitrophenol, $2.10 \mathrm{~g}$ (10.55 mmol) of phenacyl bromide, $2.62 \mathrm{~g}(19.00 \mathrm{mmol})$ of $\mathrm{K}_{2} \mathrm{CO}_{3}$ and purified by recrystallization from acetone/hexane $(84 \%$ yield). The product obtained was an orange crystalline solid (mp 148-150 $\left.{ }^{\circ} \mathrm{C}\right) .{ }^{1} \mathrm{H}$ NMR $\left(600 \mathrm{MHz}, \mathrm{CDCl}_{3}\right) \delta 8.20(\mathrm{~d}$, $J 9.0 \mathrm{~Hz}, 2 \mathrm{H}, \mathrm{Ar}-\mathrm{H}$ ), 7.99 (d, J 7.2 Hz, 2H, Ar-H), 7.66 (t, $J 7.2 \mathrm{~Hz}, 1 \mathrm{H}, \mathrm{Ar}-\mathrm{H}), 7.54$ (t, J 9.0 Hz, 2H, Ar-H), 6.99 (d, $J 9.0 \mathrm{~Hz}, 2 \mathrm{H}, \mathrm{Ar}-\mathrm{H}), 5.43\left(\mathrm{~s}, 2 \mathrm{H}, \mathrm{CH}_{2}\right) ;{ }^{13} \mathrm{C} \mathrm{NMR}(150 \mathrm{MHz}$, $\left.\mathrm{CDCl}_{3}\right) \delta 192.8,163.0,142.1,134.4,134.0,129.1,128.0$, 125.9, 114.8, 70.6. HREIMS $\mathrm{m} / \mathrm{z}, 280.0581[\mathrm{M}+\mathrm{Na}]^{+}$ (calcd. for $\mathrm{C}_{14} \mathrm{H}_{11} \mathrm{NNaO}_{4}{ }^{+}, 280.0580$ ).

\section{2-(3,5-Dichlorophenoxy)-1-phenylethanone (3b)}

Obtained according to the general procedure from $0.83 \mathrm{~g}$
(5.07 mmol) of 2,4-dichlorophenol, $1.00 \mathrm{~g}(5.02 \mathrm{mmol})$ of phenacyl bromide and $1.25 \mathrm{~g}(9.04 \mathrm{mmol})$ of $\mathrm{K}_{2} \mathrm{CO}_{3}$ and purified by recrystallization from acetone/hexane $(42 \%$ yield). The product obtained was a light brown crystalline solid (mp 74-75 $\left.{ }^{\circ} \mathrm{C}\right) .{ }^{1} \mathrm{H}$ NMR $\left(600 \mathrm{MHz}, \mathrm{CDCl}_{3}\right) \delta 8.00$ (d, J 7.2 Hz, 2H, Ar-H), 7.63 (t, J 7.2 Hz, 1H, Ar-H), 7.50 (t, J 7.2 Hz, 2H, Ar-H), 7.38 (d, J $3.0 \mathrm{~Hz}, 1 \mathrm{H}), 7.13$ (dd, $J_{1}$ $\left.9.0 \mathrm{~Hz}, J_{2} 3.0 \mathrm{~Hz}, 1 \mathrm{H}, \mathrm{Ar}-\mathrm{H}\right), 6.78$ (d, J $\left.9.0 \mathrm{~Hz}, 1 \mathrm{H}, \mathrm{Ar}-\mathrm{H}\right)$, $5.34\left(\mathrm{~s}, 2 \mathrm{H}, \mathrm{CH}_{2}\right) ;{ }^{13} \mathrm{C} \mathrm{NMR}\left(150 \mathrm{MHz}, \mathrm{CDCl}_{3}\right) \delta 193.7$, 152.7, 134.3, 134.3, 130.4, 129.0, 128.3, 127.7, 127.0, 124.3, 115.1, 72.1. HREIMS $\mathrm{m} / \mathrm{z} 302.9949[\mathrm{M}+\mathrm{Na}]^{+}$ (calcd. for $\mathrm{C}_{14} \mathrm{H}_{10} \mathrm{Cl}_{2} \mathrm{NaO}_{2}{ }^{+}, 302.9951$ ).

\section{2-(4-Nitro-phenoxy)-1-phenyl-propan-1-one (3c)}

Obtained according to the general procedure from $0.55 \mathrm{~g}$ (3.93 mmol) of 4-nitrophenol, $0.82 \mathrm{~g}(3.85 \mathrm{mmol})$ of 2-bromopropiophenone and $0.96 \mathrm{~g}(6.93 \mathrm{mmol})$ of $\mathrm{K}_{2} \mathrm{CO}_{3}$ and purified by recrystallization from methanol ( $91 \%$ yield). The product obtained was a white crystalline solid (mp 78-80 $\left.{ }^{\circ} \mathrm{C}\right) .{ }^{1} \mathrm{H}$ NMR $\left(600 \mathrm{MHz}, \mathrm{CDCl}_{3}\right) \delta 8.14$ (d, $J 9.0 \mathrm{~Hz}, 2 \mathrm{H}, \mathrm{Ar}-\mathrm{H}), 8.04$ (d, J 7.8 Hz, 2H, Ar-H), 7.63 (t, $J 7.8 \mathrm{~Hz}, 1 \mathrm{H}, \mathrm{Ar}-\mathrm{H}), 7.51$ (t, J 7.8 Hz, 2H, Ar-H), 6.90 (d, $J 9.0 \mathrm{~Hz}, 2 \mathrm{H}, \mathrm{Ar}-\mathrm{H}), 5.63$ (q, J $6.6 \mathrm{~Hz}, 1 \mathrm{H}, \mathrm{CH}), 1.78$ (d, $\left.J 6.6 \mathrm{~Hz}, 3 \mathrm{H}, \mathrm{CH}_{3}\right) ;{ }^{13} \mathrm{C} \mathrm{NMR}\left(150 \mathrm{MHz}, \mathrm{CDCl}_{3}\right) \delta 197.2$, 162.4, 142.0, 134.2, 133.7, 129.0, 128.7, 126.0, 115.0, 76.9, 18.8. HREIMS $\mathrm{m} / \mathrm{z} 294.0737[\mathrm{M}+\mathrm{Na}]^{+}$(calcd. for $\left.\mathrm{C}_{15} \mathrm{H}_{13} \mathrm{NNaO}_{4}{ }^{+}, 294.0737\right)$.

\section{2-Pentachlorophenyloxy-1-phenyl-ethanone (3d)}

Obtained according to the general procedure from $0.68 \mathrm{~g}$ ( $2.56 \mathrm{mmol})$ of pentachlorophenol, $0.50 \mathrm{~g}(2.51 \mathrm{mmol})$ of phenacyl bromide and $0.62 \mathrm{~g}(4.52 \mathrm{mmol})$ of $\mathrm{K}_{2} \mathrm{CO}_{3}$ and purified by recrystallization from methanol/ $\mathrm{CH}_{2} \mathrm{Cl}_{2}(100 \%$ yield). The product obtained was a white crystalline solid (mp 125-127 $\left.{ }^{\circ} \mathrm{C}\right) .{ }^{1} \mathrm{H}$ NMR $\left(600 \mathrm{MHz}, \mathrm{CDCl}_{3}\right) \delta 7.97$ (d, $J 7.2 \mathrm{~Hz}, 2 \mathrm{H}, \mathrm{Ar}-\mathrm{H}), 7.63$ (t, J 7.2 Hz, 1H, Ar-H), 7.51 (t, J 7.2 Hz, 2H, Ar-H), 5.30 (s, $\left.2 \mathrm{H}, \mathrm{CH}_{2}\right) ;{ }^{13} \mathrm{C} \mathrm{NMR}(150 \mathrm{MHz}$, $\left.\mathrm{CDCl}_{3}\right) \delta 192.1,151.2,134.3,134.2,132.2,130.2,129.1$, 128.3, 128.2, 74.8. HREIMS $\mathrm{m} / \mathrm{z}, 406.8745[\mathrm{M}+\mathrm{Na}]^{+}$ (calcd. for $\mathrm{C}_{14} \mathrm{H}_{7} \mathrm{Cl}_{5} \mathrm{NaO}_{2}{ }^{+}, 406.8752$ ).

\section{1-Phenyl-2-m-tolyloxy-ethanone (3e)}

Obtained according to the general procedure from $0.28 \mathrm{~g}$ (2.56 mmol) of $m$-cresol, $0.50 \mathrm{~g}$ ( $2.51 \mathrm{mmol})$ of phenacyl bromide and $0.62 \mathrm{~g}(4.52 \mathrm{mmol})$ of $\mathrm{K}_{2} \mathrm{CO}_{3}$ and purified by recrystallization from methanol (69\% yield). The product obtained was a yellow crystalline solid (mp 70-72 ${ }^{\circ} \mathrm{C}$ ). ${ }^{1} \mathrm{H}$ NMR $\left(600 \mathrm{MHz}, \mathrm{CDCl}_{3}\right) \delta 8.01(\mathrm{~d}, J 7.8 \mathrm{~Hz}, 2 \mathrm{H}, \mathrm{Ar}-\mathrm{H})$, $7.61(\mathrm{t}, J 7.8 \mathrm{~Hz}, 1 \mathrm{H}, \mathrm{Ar}-\mathrm{H}), 7.50(\mathrm{t}, J 7.8 \mathrm{~Hz}, 2 \mathrm{H}, \mathrm{Ar}-\mathrm{H}), 7.16$ (t, J 7.8 Hz, 1H, Ar-H), 6.80 (d, J 7.8 Hz, 1H, Ar-H), 6.78 (s, 1H, Ar-H), 6.74 (dd, $\left.J_{1} 7.8 \mathrm{~Hz}, J_{2} 1.8 \mathrm{~Hz}, 1 \mathrm{H}, \mathrm{Ar}-\mathrm{H}\right), 5.24$ (s, 
$\left.2 \mathrm{H}, \mathrm{CH}_{2}\right), 2.32\left(\mathrm{~s}, 3 \mathrm{H}, \mathrm{CH}_{3}\right) ;{ }^{13} \mathrm{CNMR}\left(150 \mathrm{MHz}, \mathrm{CDCl}_{3}\right) \delta$ 194.7, 158.1, 139.7, 134.7, 133.8, 129.3, 128.8, 128.2, 122.5, 115.7, 111.6, 70.8, 21.5. HREIMS $m / z$ 249.0891 [M + Na $]^{+}$ (calcd. for $\mathrm{C}_{15} \mathrm{H}_{14} \mathrm{NaO}_{2}{ }^{+}, 249.0886$ ).

\section{2-(3,5-Dichlorophenoxy)-1-phenylpropan-1-one (3f)}

Obtained according to the general procedure from $0.39 \mathrm{~g}$ (2.40 mmol) of 2,4-dichlorophenol, $0.50 \mathrm{~g}(2.35 \mathrm{mmol})$ of 2-bromopropiophenone and $0.58 \mathrm{~g}(4.23 \mathrm{mmol})$ of $\mathrm{K}_{2} \mathrm{CO}_{3}$ and purified by column chromatography in hexane/ acetate (80:20) (54\% yield). The product was obtained as a colorless oil. ${ }^{1} \mathrm{H}$ NMR $\left(600 \mathrm{MHz}, \mathrm{CDCl}_{3}\right) \delta 8.08(\mathrm{~d}$, $J 7.2 \mathrm{~Hz}, 2 \mathrm{H}, \mathrm{Ar}-\mathrm{H}), 7.59$ (t, J 7.2 Hz, 1H, Ar-H), 7.47 (t, $J 7.2 \mathrm{~Hz}, 2 \mathrm{H}, \mathrm{Ar}-\mathrm{H}), 7.35$ (d, $J 2.6 \mathrm{~Hz}, 1 \mathrm{H}, \mathrm{Ar}-\mathrm{H}), 7.06$ (dd, $\left.J_{1} 8.8 \mathrm{~Hz}, J_{2} 2.6 \mathrm{~Hz}, 1 \mathrm{H}, \mathrm{Ar}-\mathrm{H}\right), 6.72(\mathrm{~d}, J 8.8 \mathrm{~Hz}, 1 \mathrm{H}$, Ar-H), 5.40 (q, J $6.8 \mathrm{~Hz}, 1 \mathrm{H}, \mathrm{CH}), 1.78$ (d, J $8.8 \mathrm{~Hz}, 3 \mathrm{H}$, $\left.\mathrm{CH}_{3}\right) ;{ }^{13} \mathrm{C}$ NMR $\left(150 \mathrm{MHz}, \mathrm{CDCl}_{3}\right) \delta 194.7,158.1,139.7$, 134.7, 133.8, 129.3, 128.8, 128.2, 122.5, 115.7, 111.61, 70.8, 21.5. HREIMS $m / z 317.0115[\mathrm{M}+\mathrm{Na}]^{+}$(calcd. for $\left.\mathrm{C}_{15} \mathrm{H}_{12} \mathrm{Cl}_{2} \mathrm{NaO}_{2}^{+}, 317.0107\right)$.

\section{2-Pentachlorophenyloxy-1-phenyl-propan-1-one (3g)}

Obtained according to the general procedure from $0.64 \mathrm{~g}$ $(2.40 \mathrm{mmol})$ of pentachlorophenol, $0.50 \mathrm{~g}(2.35 \mathrm{mmol})$ of 2-bromopropiophenone and $0.58 \mathrm{~g}(4.23 \mathrm{mmol})$ of $\mathrm{K}_{2} \mathrm{CO}_{3}$ and purified by recrystallization from methanol $(66 \%$ yield). The product obtained was a light brown crystalline solid (mp 111-112 $\left.{ }^{\circ} \mathrm{C}\right) .{ }^{1} \mathrm{H}$ NMR ( $\left.600 \mathrm{MHz}, \mathrm{CDCl}_{3}\right) \delta 8.04$ (d, J 7.2 Hz, 2H, Ar-H), 7.61 (t, J 7.2 Hz, 1H, Ar-H), 7.50 (t, J 7.2 Hz, 2H, Ar-H), 5.70 (q, J 7.0 Hz, 1H, CH), $1.68(\mathrm{~d}$, $\left.J 7.0 \mathrm{~Hz}, 3 \mathrm{H}, \mathrm{CH}_{3}\right) ;{ }^{13} \mathrm{C} \mathrm{NMR}\left(150 \mathrm{MHz}, \mathrm{CDCl}_{3}\right) \delta 196.3$, 150.7, 134.5, 133.9, 132.2, 129.7, 129.1, 128.9, 128.4, 82.1, 18.8. HREIMS $\mathrm{m} / \mathrm{z} 420.8903[\mathrm{M}+\mathrm{Na}]^{+}$(calcd. for $\left.\mathrm{C}_{15} \mathrm{H}_{9} \mathrm{Cl}_{5} \mathrm{NaO}_{2}{ }^{+}, 420.8908\right)$.

\section{1-Phenyl-2-m-tolyloxy-propan-1-one (3h)}

Obtained according to the general procedure from $0.26 \mathrm{~g}(2.40 \mathrm{mmol})$ of $m$-cresol, $0.50 \mathrm{~g}(2.35 \mathrm{mmol})$ of 2-bromopropiophenone and $0.58 \mathrm{~g}(4.23 \mathrm{mmol})$ of $\mathrm{K}_{2} \mathrm{CO}_{3}$ and purified by recrystallization from methanol ( $54 \%$ yield). The product obtained was a light brown crystalline solid ( $\mathrm{mp}$ $\left.109-111^{\circ} \mathrm{C}\right) .{ }^{1} \mathrm{H}$ NMR $\left(600 \mathrm{MHz}, \mathrm{CDCl}_{3}\right) \delta 8.07(\mathrm{~d}, J 7.8 \mathrm{~Hz}$, 2H, Ar-H), 7.57 (t, J 7.8 Hz, 2H, Ar-H), $7.46(\mathrm{t}, J 7.8 \mathrm{~Hz}, 2 \mathrm{H}$, Ar-H), 7.10 (t, J 7.9 Hz, 1H, Ar-H), 6.75 (d, J 7.9 Hz, 1H, Ar-H), 7.10 (t, J 7.9 Hz, 1H, Ar-H), 6.75 (d, J 7.9 Hz, 1H, Ar-H), $6.72(\mathrm{~s}, 1 \mathrm{H}, \mathrm{Ar}-\mathrm{H}), 6.65\left(\mathrm{dd}, J_{1} 7.9 \mathrm{~Hz}, J_{2} 2.4 \mathrm{~Hz}, 1 \mathrm{H}\right.$, Ar-H), $5.45(\mathrm{q}, J 7.0 \mathrm{~Hz}, 1 \mathrm{H}, \mathrm{CH}), 2.27\left(\mathrm{~s}, 3 \mathrm{H}, \mathrm{CH}_{3}\right), 1.69$ (d, $\left.J 7.0 \mathrm{~Hz}, 3 \mathrm{H}, \mathrm{CH}_{3}\right) ;{ }^{13} \mathrm{C}$ NMR $\left(150 \mathrm{MHz}, \mathrm{CDCl}_{3}\right) \delta 199.2$, 157.6, 139.8, 134.4, 133.7, 129.4, 129.0, 128.9, 122.5, 116.3, 112.0, 76.7, 21.6, 18.8. HREIMS $m / z 263.1051[\mathrm{M}+\mathrm{Na}]^{+}$ (calcd. for $\mathrm{C}_{16} \mathrm{H}_{16} \mathrm{NaO}_{2}^{+}$, 263.1043).
1-(4-Bromophenyl)-2-(3,5-dichlorophenoxy)ethanone (3i)

Obtained according to the general procedure from $0.30 \mathrm{~g}$ (1.84 mmol) of 2,4-dichlorophenol, $0.50 \mathrm{~g}(1.80 \mathrm{mmol})$ of 2,4'-dibromoacetophenone and $0.45 \mathrm{~g}(3.24 \mathrm{mmol})$ of $\mathrm{K}_{2} \mathrm{CO}_{3}$ and purified by recrystallization from methanol/ $\mathrm{CH}_{2} \mathrm{Cl}_{2}$ (39\% yield). The product obtained was a white crystalline solid (mp 99-101 $\left.{ }^{\circ} \mathrm{C}\right) .{ }^{1} \mathrm{H}$ NMR $(600 \mathrm{MHz}$, $\left.\mathrm{CDCl}_{3}\right) \delta 7.88(\mathrm{~d}, J 8.4 \mathrm{~Hz}, 2 \mathrm{H}, \mathrm{Ar}-\mathrm{H}), 7.65(\mathrm{~d}, J 9.0 \mathrm{~Hz}$, $2 \mathrm{H}, \mathrm{Ar}-\mathrm{H}), 7.39$ (d, J $2.4 \mathrm{~Hz}, 1 \mathrm{H}, \mathrm{Ar}-\mathrm{H}), 7.14$ (dd, $J_{1} 9.0 \mathrm{~Hz}$, $\left.J_{2} 2.4 \mathrm{~Hz}, 1 \mathrm{H}, \mathrm{Ar}-\mathrm{H}\right), 6.78$ (d, J $\left.9.0 \mathrm{~Hz}, 1 \mathrm{H}, \mathrm{Ar}-\mathrm{H}\right), 5.25$ (s, 2H, $\left.\mathrm{CH}_{2}\right) ;{ }^{13} \mathrm{C} \mathrm{NMR}\left(150 \mathrm{MHz}, \mathrm{CDCl}_{3}\right) \delta 193.1,152.4$, $132.9,132.2,130.4,129.8,129.5,127.6,127.2,124.2$, 114.9, 72.1. HREIMS $\mathrm{m} / z 380.9042[\mathrm{M}+\mathrm{Na}]^{+}$(calcd. for $\left.\mathrm{C}_{14} \mathrm{H}_{9} \mathrm{BrCl}_{2} \mathrm{NaO}_{2}^{+}, 380.9056\right)$.

\section{1-(4-Bromophenyl)-2-( $m$-tolyloxy)ethanone (3j)}

Obtained according to the general procedure from $0.10 \mathrm{~g}(0.92 \mathrm{mmol})$ of $m$-cresol, $0.25 \mathrm{~g}(0.90 \mathrm{mmol})$ of 2,4'-dibromoacetophenone and $0.23 \mathrm{~g}(1.62 \mathrm{mmol})$ of $\mathrm{K}_{2} \mathrm{CO}_{3}$ and purified by recrystallization from methanol (69\% yield). The product obtained was a light brown crystalline solid (mp 91-93 $\left.{ }^{\circ} \mathrm{C}\right) .{ }^{1} \mathrm{H} \mathrm{NMR}\left(600 \mathrm{MHz}, \mathrm{CDCl}_{3}\right)$ $\delta 7.88(\mathrm{~d}, J 8.4 \mathrm{~Hz}, 2 \mathrm{H}, \mathrm{Ar}-\mathrm{H}), 7.63(\mathrm{~d}, J 8.4 \mathrm{~Hz}, 2 \mathrm{H}, \mathrm{Ar}-\mathrm{H})$, 7.16 (t, J 8.0 Hz, 1H, Ar-H), 6.81 (d, J 8.0 Hz, 1H, Ar-H), 6.76 (s, 1H, Ar-H), 6.72 (d, J 8.0 Hz, 1H, Ar-H), 5.17 (s, $\left.2 \mathrm{H}, \mathrm{CH}_{2}\right), 2.32\left(\mathrm{~s}, 3 \mathrm{H}, \mathrm{CH}_{3}\right) ;{ }^{13} \mathrm{C} \mathrm{NMR}\left(150 \mathrm{MHz}, \mathrm{CDCl}_{3}\right)$ $\delta$ 194.1, 157.9, 139.8, 133.4, 132.1, 129.8, 129.3, 129.1, 122.7, 115.6, 111.5, 70.9, 21.5. HREIMS $\mathrm{m} / \mathrm{z} 326.9997$ $[\mathrm{M}+\mathrm{Na}]^{+}$(calcd. for $\mathrm{C}_{15} \mathrm{H}_{13} \mathrm{BrNaO}_{2}^{+}, 326.9992$ ).

2-Oxo-2-phenylethyl(2E)-3-[4-(2-oxo-2-phenylethoxy) phenyl]prop-2-enoate (4a)

Obtained according to the general procedure from $0.21 \mathrm{~g}(1.28 \mathrm{mmol})$ of $p$-hydroxycinnamic acid, $0.50 \mathrm{~g}$ ( $2.51 \mathrm{mmol})$ of phenacyl bromide and $0.62 \mathrm{~g}(4.52 \mathrm{mmol})$ of $\mathrm{K}_{2} \mathrm{CO}_{3}$ and purified by recrystallization from acetone (55\% yield). The product obtained was a colorless crystalline solid (mp 145-147 ${ }^{\circ} \mathrm{C}$ ). ${ }^{1} \mathrm{H}$ NMR (250 MHz, DMSO- $d_{6}$ ) $\delta 8.03(\mathrm{~d}, J 8.8 \mathrm{~Hz}, 2 \mathrm{H}, \mathrm{Ar}-\mathrm{H}), 8.00(\mathrm{~d}, J 8.8 \mathrm{~Hz}, 2 \mathrm{H}$, Ar-H), 7.70 (t, $J 8.8 \mathrm{~Hz}, 4 \mathrm{H}, \mathrm{Ar}-\mathrm{H}$; d, $J 15.8 \mathrm{~Hz}, 1 \mathrm{H}, \mathrm{CH}$ ), 7.50-7.63 (m, 4H, Ar-H), 7.04 (d, J 8.5 Hz, 2H, Ar-H), 6.65 (d, J $15.8 \mathrm{~Hz}, 1 \mathrm{H}, \mathrm{CH}), 5.68\left(\mathrm{~s}, 2 \mathrm{H}, \mathrm{CH}_{2}\right), 5.60\left(\mathrm{~s}, 2 \mathrm{H}, \mathrm{CH}_{2}\right)$; ${ }^{13} \mathrm{C}$ NMR $\left(62.5 \mathrm{MHz}\right.$, DMSO- $\left.d_{6}\right) \delta 194.2,193.0,165.9$, $160.0,145.1,134.3,134.0,133.9,130.2,128.9,128.9$, 127.9, 127.8, 126.9, 115.1, 114.8, 70.2, 66.4. HREIMS $\mathrm{m} / \mathrm{z} 401.1389[\mathrm{M}+\mathrm{H}]^{+}$(calcd. for $\left.\mathrm{C}_{25} \mathrm{H}_{21} \mathrm{O}_{5}{ }^{+}, 401.1384\right)$.

(E)-2-Oxo-2-phenylethyl 3-(3-methoxy-4-(2-oxo-2-phenylethoxy)phenyl)acrylate (4b)

Obtained according to the general procedure from $0.25 \mathrm{~g}(1.28 \mathrm{mmol})$ of ferulic acid, $0.50 \mathrm{~g}(2.51 \mathrm{mmol})$ of 
phenacyl bromide and $0.57 \mathrm{~g}(4.52 \mathrm{mmol})$ of $\mathrm{K}_{2} \mathrm{CO}_{3}$ and purified by recrystallization from methanol ( $74 \%$ yield). The product obtained was a white solid $\left(\mathrm{mp} 135-137^{\circ} \mathrm{C}\right)$. ${ }^{1} \mathrm{H} \mathrm{NMR}\left(600 \mathrm{MHz}, \mathrm{CDCl}_{3}\right) \delta 8.01(\mathrm{~d}, J 7.3 \mathrm{~Hz}, 2 \mathrm{H}, \mathrm{Ar}-\mathrm{H})$, $7.96(\mathrm{~d}, J 7.3 \mathrm{~Hz}, 2 \mathrm{H}, \mathrm{Ar}-\mathrm{H}), 7.73(\mathrm{~d}, J 16.1 \mathrm{~Hz}, 1 \mathrm{H}, \mathrm{CH})$, $7.62\left(\mathrm{td}, J_{1} 7.3 \mathrm{~Hz}, J_{2} 3.6 \mathrm{~Hz}, 2 \mathrm{H}, \mathrm{Ar}-\mathrm{H}\right), 7.50\left(\mathrm{td}, J_{1} 7.8 \mathrm{~Hz}\right.$, $\left.J_{2} 2 \mathrm{~Hz}, 4 \mathrm{H}, \mathrm{Ar}-\mathrm{H}\right), 7.12$ (d, J $\left.1.8 \mathrm{~Hz}, 1 \mathrm{H}, \mathrm{Ar}-\mathrm{H}\right), 7.06$ (dd, $\left.J_{1} 8.4 \mathrm{~Hz}, J_{2} 1.8 \mathrm{~Hz}, 1 \mathrm{H}, \mathrm{Ar}-\mathrm{H}\right), 6.80(\mathrm{~d}, J 8.4 \mathrm{~Hz}, 1 \mathrm{H}, \mathrm{Ar}-\mathrm{H})$, $6.48(\mathrm{~d}, J 16.1 \mathrm{~Hz}, 1 \mathrm{H}, \mathrm{CH}), 5.47\left(\mathrm{~s}, 2 \mathrm{H}, \mathrm{CH}_{2}\right), 5.40(\mathrm{~s}, 2 \mathrm{H}$, $\mathrm{CH}_{2}$ ), 3.93 (s, $\left.3 \mathrm{H}, \mathrm{OCH}_{3}\right) ;{ }^{13} \mathrm{C} \mathrm{NMR}\left(150 \mathrm{MHz}, \mathrm{CDCl}_{3}\right)$ $\delta$ 193.8, 192.4, 166.4, 149.8, 149.7, 145.8, 134.4, 134.4, $134.0,133.9,128.9,128.6,128.1,127.8,122.5,115.3$, 113.9, 110.8, 71.6, 66.0, 56.0. HREIMS $\mathrm{m} / \mathrm{z} 453.1307$ $[\mathrm{M}+\mathrm{Na}]^{+}$(calcd. for $\left.\mathrm{C}_{26} \mathrm{H}_{22} \mathrm{NaO}_{6}^{+}, 453.1309\right)$.

(E) - 1 - ( 4 - Methoxyphenyl) - 1-oxopropan-2-yl 3-(4-((1-(4-methoxyphenyl)-1-oxopropan-2-yl)oxy)phenyl) acrylate (4c)

Obtained according to the general procedure from $0.10 \mathrm{~g}(0.53 \mathrm{mmol})$ of $p$-hydroxycinnamic acid, $0.25 \mathrm{~g}$ (1.03 mmol) of 4-methoxy-8-bromopropiophenone and $0.26 \mathrm{~g}(1.85 \mathrm{mmol})$ of $\mathrm{K}_{2} \mathrm{CO}_{3}$ and purified by recrystallization from methanol ( $71 \%$ yield). The product obtained was a colorless crystalline solid (mp 142-144 ${ }^{\circ} \mathrm{C}$ ). ${ }^{1} \mathrm{H}$ NMR $\left(400 \mathrm{MHz}\right.$, DMSO- $\left.d_{6}\right) \delta 8.12(\mathrm{~d}, J 8.8 \mathrm{~Hz}, 2 \mathrm{H}$, Ar-H), 8.05 (d, J $8.8 \mathrm{~Hz}, 2 \mathrm{H}, \mathrm{Ar}-\mathrm{H}), 7.70$ (d, J $8.8 \mathrm{~Hz}, 2 \mathrm{H}$, Ar-H), 7.64 (d, J 16.0 Hz, 1H, CH), 7.19-7.08 (m, 4H, Ar-H), 6.94 (d, J $8.8 \mathrm{~Hz}, 2 \mathrm{H}, \mathrm{Ar}-\mathrm{H}), 6.61$ (d, J $16.0 \mathrm{~Hz}, 1 \mathrm{H}$, $\mathrm{CH}), 6.16-6.06(\mathrm{~m}, 2 \mathrm{H}, \mathrm{CH}), 3.91\left(\mathrm{~s}, 3 \mathrm{H}, \mathrm{OCH}_{3}\right), 3.90(\mathrm{~s}$, $\left.3 \mathrm{H}, \mathrm{OCH}_{3}\right), 1.59\left(\mathrm{~d}, J 7.0 \mathrm{~Hz}, 3 \mathrm{H}, \mathrm{CH}_{3}\right), 1.52(\mathrm{~d}, J 7.0 \mathrm{~Hz}$, $\left.3 \mathrm{H}, \mathrm{CH}_{3}\right) ;{ }^{13} \mathrm{C}$ NMR $\left(100 \mathrm{MHz}\right.$, DMSO- $\left.d_{6}\right) \delta 196.1,195.1$, $165.8,163.8,163.6,159.2,144.9,130.9,130.8,130.3$, $126.9,126.7,126.7,115.3,115.0,114.3,114.2,74.3,71.2$, 55.7, 18.5, 17.2. HREIMS $m / z 489.1941[\mathrm{M}+\mathrm{H}]^{+}$(calcd. for $\mathrm{C}_{29} \mathrm{H}_{29} \mathrm{O}_{7}^{+}$, 489.1942).

\section{3-[3-(2-Oxo-2-phenyl-ethoxy)-phenyl]-acrylic acid (5a)}

Obtained according to the general procedure from $0.42 \mathrm{~g}$ (2.56 mmol) 3-hydroxycinnamic acid, $1.00 \mathrm{~g}$ (5.02 mmol) of phenacyl bromide and $1.24 \mathrm{~g}(9.00 \mathrm{mmol})$ of $\mathrm{K}_{2} \mathrm{CO}_{3}$ and purified by recrystallization from methanol (76\% yield). The product obtained was a white crystalline solid (mp 139-141 $\left.{ }^{\circ} \mathrm{C}\right) .{ }^{1} \mathrm{H}$ NMR $\left(600 \mathrm{MHz}, \mathrm{CDCl}_{3}\right) \delta 8.02$ (d, J 7.3 Hz, 2H, Ar-H), 7.96 (d, J 7.3 Hz, 2H, Ar-H), 7.76 (d, J 16.0 Hz, 1H, CH), 7.59-7.68 (m, 2H, Ar-H), 7.48-7.56 (m, 4H, Ar-H), 7.32 (t, J $8.0 \mathrm{~Hz}, 1 \mathrm{H}, \mathrm{Ar}-\mathrm{H}), 7.19$ (d, $J 8.0 \mathrm{~Hz}, 1 \mathrm{H}, \mathrm{Ar}-\mathrm{H}), 7.12$ (s, $1 \mathrm{H}, \mathrm{Ar}-\mathrm{H}), 7.00$ (dd, $J_{1} 8.0 \mathrm{~Hz}$, $\left.J_{2} 2.2 \mathrm{~Hz}, 1 \mathrm{H}, \mathrm{Ar}-\mathrm{H}\right), 6.57$ (d, J $\left.16.0 \mathrm{~Hz}, 1 \mathrm{H}, \mathrm{CH}\right), 5.47$ (s, $\left.2 \mathrm{H}, \mathrm{CH}_{2}\right), 5.32\left(\mathrm{~s}, 2 \mathrm{H}, \mathrm{CH}_{2}\right) ;{ }^{13} \mathrm{C} \mathrm{NMR}\left(150 \mathrm{MHz}, \mathrm{CDCl}_{3}\right)$ $\delta$ 194.1, 192.4 166.3, 158.5, 145.9, 135.9, 134.6, 134.4, $134.1,134.0,130.2,129.0,129.0,128.2,128.0,122.0$,
117.7, 117.3, 114.2, 70.9, 66.3. HREIMS $\mathrm{m} / \mathrm{z} 423.1208$ $[\mathrm{M}+\mathrm{Na}]^{+}$(calcd. for $\mathrm{C}_{25} \mathrm{H}_{20} \mathrm{NaO}_{5}{ }^{+}, 423.1203$ ).

(E)-2-(4-Nitrophenyl)-2-oxoethyl 3-(3-(2-(4-nitrophenyl)2-oxoethoxy)phenyl)acrylate (5b)

Obtained according to the general procedure from $0.09 \mathrm{~g}(0.52 \mathrm{mmol})$ of 3-hydroxycinnamic acid, $0.25 \mathrm{~g}$ $(1.02 \mathrm{mmol})$ of $p$-nitrophenacyl bromide and $0.25 \mathrm{~g}$ $(1.84 \mathrm{mmol})$ of $\mathrm{K}_{2} \mathrm{CO}_{3}$ and purified by recrystallization from methanol ( $45 \%$ yield). The product obtained was a light brown crystalline solid (mp 101-103 ${ }^{\circ} \mathrm{C}$ ). ${ }^{1} \mathrm{H}$ NMR (600 MHz, $\left.\mathrm{CDCl}_{3}\right) \delta 8.20-8.14$ (m, 2H, Ar-H), 7.80-7.73 (m, 2H, Ar-H), 7.71-7.62 (m, 2H), 7.56-7.46 (m, 3H, Ar-H), 7.26 (t, J 7.8 Hz, 1H, Ar-H), 7.09 (d, J 7.7 Hz, 1H, Ar-H), 6.85 (s, 1H, Ar-H), 6.82 (d, J 8.4 Hz, 1H, Ar-H), 6.28 (d, $J 16.1 \mathrm{~Hz}, 1 \mathrm{H}, \mathrm{CH}), 5.12\left(\mathrm{~s}, 2 \mathrm{H}, \mathrm{CH}_{2}\right), 4.91$ (s, $2 \mathrm{H}, \mathrm{CH}_{2}$ ); ${ }^{13} \mathrm{C} \mathrm{NMR}\left(150 \mathrm{MHz}, \mathrm{CDCl}_{3}\right) \delta 198.9,197.4,165.6,157.5$, 147.3, 146.3, 145.8, 135.5, 134.7, 134.4, 134.4, 134.2, $131.5,131.4,130.1,128.8,128.8,124.0,123.8,122.2$, 117.0, 116.8, 114.1, 72.0, 67.6. HREIMS $\mathrm{m} / \mathrm{z} .513 .0901$ $[\mathrm{M}+\mathrm{Na}]^{+}$(calcd. for $\left.\mathrm{C}_{25} \mathrm{H}_{18} \mathrm{~N}_{2} \mathrm{NaO}_{9}{ }^{+}, 513.0905\right)$.

\section{2-Oxo-2-phenylethyl cinnamate (6a)}

Obtained according to the general procedure from $0.38 \mathrm{~g}(2.56 \mathrm{mmol})$ of cinnamic acid, $0.50 \mathrm{~g}(2.51 \mathrm{mmol})$ of phenacyl bromide and $0.62 \mathrm{~g}(4.52 \mathrm{mmol})$ of $\mathrm{K}_{2} \mathrm{CO}_{3}$ and purified by recrystallization from acetone ( $86 \%$ yield). The product obtained was a colorless crystalline solid (mp 141-143 $\left.{ }^{\circ} \mathrm{C}\right) .{ }^{1} \mathrm{H}$ NMR $\left(600 \mathrm{MHz}, \mathrm{CDCl}_{3}\right) \delta 7.96(\mathrm{~d}$, $J 7.2 \mathrm{~Hz}, 2 \mathrm{H}, \mathrm{Ar}-\mathrm{H}), 7.81(\mathrm{~d}, J 16.1 \mathrm{~Hz}, 1 \mathrm{H}, \mathrm{CH}), 7.62$ (t, $J 7.2 \mathrm{~Hz}, 1 \mathrm{H}, \mathrm{Ar}-\mathrm{H}), 7.55$ (s, 2H, Ar-H), 7.50 (t, J 7.2 Hz, $2 \mathrm{H}, \mathrm{Ar}-\mathrm{H}), 7.40$ (s, 3H, Ar-H), 6.60 (d, J $16.1 \mathrm{~Hz}, 1 \mathrm{H}$, $\mathrm{CH}), 5.80\left(\mathrm{~s}, 2 \mathrm{H}, \mathrm{CH}_{2}\right) ;{ }^{13} \mathrm{C}$ NMR $\left(150 \mathrm{MHz}, \mathrm{CDCl}_{3}\right)$ $\delta$ 192.4, 166.4, 146.3, 134.5, 134.4, 134.0, 130.7, 129.1, 129.0, 128.4, 128.0, 117.2, 66.3. HREIMS $\mathrm{m} / \mathrm{z} 289.0836$ $[\mathrm{M}+\mathrm{Na}]^{+}$(calcd. for $\mathrm{C}_{17} \mathrm{H}_{14} \mathrm{NaO}_{3}{ }^{+}, 289.0836$ ).

\section{2-(4-Nitrophenyl)-2-oxoethyl cinnamate (6b)}

Obtained according to the general procedure from $0.38 \mathrm{~g}(2.59 \mathrm{mmol})$ of cinnamic acid, $0.62 \mathrm{~g}(2.54 \mathrm{mmol})$ of 4-nitrophenacyl bromide and $0.63 \mathrm{~g}(4.56 \mathrm{mmol})$ of $\mathrm{K}_{2} \mathrm{CO}_{3}$ and purified by recrystallization from acetone/hexane ( $75 \%$ yield). The product obtained was a light yellow crystalline solid (mp 157-158 $\left.{ }^{\circ} \mathrm{C}\right) .{ }^{1} \mathrm{H} \mathrm{NMR}\left(600 \mathrm{MHz}, \mathrm{CDCl}_{3}\right) \delta 8.36$ (d, $J 8.8 \mathrm{~Hz}, 2 \mathrm{H}, \mathrm{Ar}-\mathrm{H}), 8.12$ (d, $J 8.8 \mathrm{~Hz}, 2 \mathrm{H}, \mathrm{Ar}-\mathrm{H}), 7.81$ (d, J $16.0 \mathrm{~Hz}, 1 \mathrm{H}, \mathrm{CH}), 7.52-7.63(\mathrm{~m}, 2 \mathrm{H}, \mathrm{Ar}-\mathrm{H}), 7.36-7.45$ (m, 3H, Ar-H), 6.58 (d, J $16.0 \mathrm{~Hz}, 1 \mathrm{H}, \mathrm{CH}), 5.46$ (s, 2H, $\left.\mathrm{CH}_{2}\right) ;{ }^{13} \mathrm{C}$ NMR $\left(150 \mathrm{MHz}, \mathrm{CDCl}_{3}\right) \delta 191.3,166.1,150.7$, 146.7, 138.8, 134.1, 130.7, 129.0, 129.0, 128.3, 127.9, 124.1, 116.4, 66.2. HREIMS $\mathrm{m} / \mathrm{z} 334.0696[\mathrm{M}+\mathrm{Na}]^{+}$ (calcd. for $\mathrm{C}_{17} \mathrm{H}_{13} \mathrm{NNaO}_{5}{ }^{+}, 334.0686$ ). 
1-Oxo-1-phenylpropan-2-yl cinnamate (6c)

Obtained according to the general procedure from $0.36 \mathrm{~g}(2.40 \mathrm{mmol})$ of cinnamic acid, $0.50 \mathrm{~g}(2.35 \mathrm{mmol})$ of 2-bromopropiophenone and $0.58 \mathrm{~g}(4.23 \mathrm{mmol})$ of $\mathrm{K}_{2} \mathrm{CO}_{3}$ and purified by recrystallization from methanol (57\% yield). The product obtained was a white crystalline solid (mp 70-71 ${ }^{\circ} \mathrm{C}$ ). ${ }^{1} \mathrm{H}$ NMR (600 MHz, $\left.\mathrm{CDCl}_{3}\right) \delta 7.99$ (d, J 7.2 Hz, 2H, Ar-H), 7.74 (d, J 16.2 Hz, 1H, CH), 7.59 (t, J 7.2 Hz, 1H, Ar-H), 7.51-7.55 (m, 2H, Ar-H), 7.49 (t, J 7.2 Hz, 2H, Ar-H), 7.37-7.40 (m, 3H, Ar-H), 6.54 (d, $J 16.2 \mathrm{~Hz}, 1 \mathrm{H}, \mathrm{CH}), 6.12(\mathrm{q}, J 7.0 \mathrm{~Hz}, 1 \mathrm{H}, \mathrm{CH}), 1.61$ (d, $\left.J 7.0 \mathrm{~Hz}, 3 \mathrm{H}, \mathrm{CH}_{3}\right) ;{ }^{13} \mathrm{C} \mathrm{NMR}\left(150 \mathrm{MHz}, \mathrm{CDCl}_{3}\right) \delta 196.9$, $166.2,145.9,134.5,134.3,133.5,130.5,128.9,128.8$, 128.5, 128.2, 117.2, 71.4, 17.2. HREIMS $\mathrm{m} / \mathrm{z} 303.0996$ $[\mathrm{M}+\mathrm{Na}]^{+}$(calcd. for $\mathrm{C}_{18} \mathrm{H}_{16} \mathrm{NaO}_{3}{ }^{+}, 303.0992$ ).

\section{2-(4-Chlorophenyl)-2-oxoethyl cinnamate (6d)}

Obtained according to the general procedure from $0.34 \mathrm{~g}(2.32 \mathrm{mmol})$ of cinnamic acid, $0.53 \mathrm{~g}(2.27 \mathrm{mmol})$ of 2-bromo-4'-chloroacetophenone and $0.57 \mathrm{~g}(4.10 \mathrm{mmol})$ of $\mathrm{K}_{2} \mathrm{CO}_{3}$ and purified by recrystallization from acetone (59\% yield). The product obtained was a white crystalline solid (mp 128-130 $\left.{ }^{\circ} \mathrm{C}\right) .{ }^{1} \mathrm{H}$ NMR $\left(400 \mathrm{MHz}, \mathrm{CDCl}_{3}\right) \delta 7.89(\mathrm{~d}$, $J 8.6 \mathrm{~Hz}, 2 \mathrm{H}, \mathrm{Ar}-\mathrm{H}), 7.80(\mathrm{~d}, J 16.0 \mathrm{~Hz}, 1 \mathrm{H}, \mathrm{CH}), 7.52-7.56$ (m, 2H, Ar-H), 7.46 (d, J 8.6 Hz, 2H, Ar-H), 7.38-7.41 (m, 3H, Ar-H), 6.58 (d, J $16.0 \mathrm{~Hz}, 1 \mathrm{H}, \mathrm{CH}), 5.42$ (s, 2H, $\left.\mathrm{CH}_{2}\right) ;{ }^{13} \mathrm{C} \mathrm{NMR}\left(100 \mathrm{MHz}, \mathrm{CDCl}_{3}\right) \delta 191.2,166.1,146.2$, $140.3,134.1,132.5,130.5,129.2,128.9,128.5,128.2$, 116.7, 65.9. HREIMS $\mathrm{m} / \mathrm{z} 323.0451[\mathrm{M}+\mathrm{Na}]^{+}$(calcd. for $\left.\mathrm{C}_{17} \mathrm{H}_{13} \mathrm{ClNaO}_{3}{ }^{+}, 323.0446\right)$.

(E)-2-Oxo-2-phenylethyl-3-(benzo[d] [1,3]dioxol-5-yl) acrylate $(6 \mathbf{e})$

Obtained according to the general procedure from $0.49 \mathrm{~g}$ (2.56 mmol) of 3,4-(methylenedioxy)cinnamic acid, $0.50 \mathrm{~g}$ $(2.51 \mathrm{mmol})$ of phenacyl bromide and $0.59 \mathrm{~g}(4.52 \mathrm{mmol})$ of $\mathrm{K}_{2} \mathrm{CO}_{3}$ and purified by recrystallization from acetone/hexane (69\% yield). The product obtained was a colorless crystalline solid (mp 144-146 $\left.{ }^{\circ} \mathrm{C}\right) .{ }^{1} \mathrm{H}$ NMR $\left(250 \mathrm{MHz}, \mathrm{CDCl}_{3}\right) \delta$ 7.95 (d, J 7.4 Hz, 2H, Ar-H), 7.71 (d, J $16.0 \mathrm{~Hz}, 1 \mathrm{H}, \mathrm{CH})$, 7.61 (t, J 7.4 Hz, 1H, Ar-H), 7.49 (t, J 7.4 Hz, 2H, Ar-H), 7.06-7.02 (m, 2H, Ar-H), 6.81 (d, J 7.9 Hz, 1H, Ar-H), 6.42 (d, J $16.0 \mathrm{~Hz}, 1 \mathrm{H}, \mathrm{CH}), 6.01\left(\mathrm{~s}, 2 \mathrm{H}, \mathrm{OCH}_{2} \mathrm{O}\right), 5.46(\mathrm{~s}, 2 \mathrm{H}$, $\left.\mathrm{CH}_{2}\right) ;{ }^{13} \mathrm{C} \mathrm{NMR}\left(62.5 \mathrm{MHz}, \mathrm{CDCl}_{3}\right) \delta 192.4,166.4,149.8$, 148.3, 145.8, 134.3, 133.8, 129.2, 128.8, 127.8, 124.7, 114.8, 108.5, 106.6, 101.6, 66.0. HREIMS $m / z 349.0478[\mathrm{M}+\mathrm{K}]^{+}$ (calcd. for $\mathrm{C}_{18} \mathrm{H}_{14} \mathrm{KO}_{5}^{+}, 349.0473$ ).

(E)-2-(4-Chlorophenyl)-2-oxoethyl-3-(3,4,5 trimethoxyphenyl)acrylate (6f)

Obtained according to the general procedure from
$1.04 \mathrm{~g}(4.37 \mathrm{mmol})$ of 3,4,5-trimethoxycinnamic acid, $1.00 \mathrm{~g}(4.28 \mathrm{mmol})$ of 2-bromo-4'-chloroacetophenone and $1.09 \mathrm{~g}(7.70 \mathrm{mmol})$ of $\mathrm{K}_{2} \mathrm{CO}_{3}$ and purified by recrystallization from acetone ( $45 \%$ yield). The product obtained was a white crystalline solid (mp 117-119 ${ }^{\circ} \mathrm{C}$ ). ${ }^{1} \mathrm{H}$ NMR $\left(400 \mathrm{MHz}, \mathrm{CDCl}_{3}\right) \delta 7.90$ (d, J $\left.8.0 \mathrm{~Hz}, 2 \mathrm{H}, \mathrm{Ar}-\mathrm{H}\right)$, $7.71(\mathrm{~d}, J 16.0 \mathrm{~Hz}, 1 \mathrm{H}, \mathrm{CH}), 7.48-7.46(\mathrm{~m}, 2 \mathrm{H}, \mathrm{Ar}-\mathrm{H})$, 6.78 (s, 2H, Ar-H), 6.50 (d, J 16.0 Hz, 1H, CH), 5.44 (s, $\left.2 \mathrm{H}, \mathrm{CH}_{2}\right), 3.89$ (s, $\left.9 \mathrm{H}, \mathrm{OCH}_{3}\right) ;{ }^{13} \mathrm{C}$ NMR $(100 \mathrm{MHz}$, $\left.\mathrm{CDCl}_{3}\right) \delta 191.2,166.1,153.3,146.2,140.3,140.3,132.5$, 129.6, 129.1, 115.9, 105.4, 65.8, 60.9, 56.1. HREIMS $\mathrm{m} / \mathrm{z} 391.0948[\mathrm{M}+\mathrm{H}]^{+}$(calcd. for $\left.\mathrm{C}_{20} \mathrm{H}_{20} \mathrm{ClO}_{6}{ }^{+}, 391.0943\right)$.

(E)-Methyl-3-(3-methoxy-4-(2-oxo-2-phenylethoxy) phenyl) acrylate $(\mathbf{7 a})$

Obtained according to the general procedure from $0.75 \mathrm{~g}(3.59 \mathrm{mmol})$ of methyl ferulate, $0.70 \mathrm{~g}(3.52 \mathrm{mmol})$ of phenacyl bromide and $0.88 \mathrm{~g}(6.34 \mathrm{mmol})$ of $\mathrm{K}_{2} \mathrm{CO}_{3}$ and purified by recrystallization from ethanol (53\% yield). The product obtained was a colorless crystalline solid (mp 105-107 $\left.{ }^{\circ} \mathrm{C}\right) .{ }^{1} \mathrm{H}$ NMR $\left(500 \mathrm{MHz}, \mathrm{CDCl}_{3}\right) \delta 8.00(\mathrm{~d}$, $J$ 8.0 Hz, 2H, Ar-H), 7.63-7.59 (m, 2H, Ar-H/CH), 7.50 (t, $J 8.0 \mathrm{~Hz}, 2 \mathrm{H}, \mathrm{Ar}-\mathrm{H}), 7.07$ (s, 1H, Ar-H), $7.02(\mathrm{~d}, J 8.0 \mathrm{~Hz}$, $1 \mathrm{H}, \mathrm{Ar}-\mathrm{H}), 6.77$ (d, J 8.0 Hz, 1H, Ar-H), $6.31(\mathrm{~d}, J 16.0 \mathrm{~Hz}$, $1 \mathrm{H}, \mathrm{CH}), 5.41\left(\mathrm{~s}, 2 \mathrm{H}, \mathrm{CH}_{2}\right), 3.92\left(\mathrm{~s}, 3 \mathrm{H}, \mathrm{OCH}_{3}\right), 3.79$ (s, $\left.3 \mathrm{H}, \mathrm{OCH}_{3}\right) ;{ }^{13} \mathrm{C}$ NMR $\left(125 \mathrm{MHz}, \mathrm{CDCl}_{3}\right) \delta 193.7,167.5$, $149.5,149.3,144.5,134.2,133.9,128.8,128.5,127.9$, 122.0, 115.9, 113.6, 110.4, 71.3, 55.9, 51.6. HREIMS $\mathrm{m} / \mathrm{z} 327.1233[\mathrm{M}+\mathrm{H}]^{+}$(calcd. for $\mathrm{C}_{19} \mathrm{H}_{19} \mathrm{O}_{5}{ }^{+}, 327.1227$ ).

3-\{4-[2-(4-Bromo-phenyl)-2-oxo-ethoxy]-3-methoxy-phenyl\}acrylic acid methyl ester (7b)

Obtained according to the general procedure from $0.19 \mathrm{~g}(0.92 \mathrm{mmol})$ of methyl ferulate, $0.25 \mathrm{~g}(0.90 \mathrm{mmol})$ of 2,4'-dibromoacetophenone and $0.22 \mathrm{~g}(1.62 \mathrm{mmol})$ of $\mathrm{K}_{2} \mathrm{CO}_{3}$ and purified by recrystallization from acetone/ $\mathrm{CH}_{2} \mathrm{Cl}_{2}$ (68\% yield). The product obtained was a light yellow crystalline solid (mp $\left.160-162{ }^{\circ} \mathrm{C}\right) .{ }^{1} \mathrm{H}$ NMR $\left(600 \mathrm{MHz}, \mathrm{CDCl}_{3}\right) \delta 7.88(\mathrm{~d}, J 8.4 \mathrm{~Hz}, 2 \mathrm{H}, \mathrm{Ar}-\mathrm{H}), 7.64$ (d, J 8.4 Hz, 2H, Ar-H), $7.61(\mathrm{~d}, J 16.2 \mathrm{~Hz}, 1 \mathrm{H}, \mathrm{CH}), 7.07$ (d, J $1.8 \mathrm{~Hz}, 1 \mathrm{H}, \mathrm{Ar}-\mathrm{H}), 7.03$ (dd, $J_{1} 8.4 \mathrm{~Hz}, J_{2} 1.8 \mathrm{~Hz}, 1 \mathrm{H}$, Ar-H), 6.79 (d, J $8.4 \mathrm{~Hz}, 1 \mathrm{H}, \mathrm{Ar}-\mathrm{H}), 6.31$ (d, J $16.2 \mathrm{~Hz}, 1 \mathrm{H}$, $\mathrm{CH}), 5.31\left(\mathrm{~s}, 2 \mathrm{H}, \mathrm{CH}_{2}\right), 3.91\left(\mathrm{~s}, 3 \mathrm{H}, \mathrm{CH}_{3}\right), 3.79\left(\mathrm{~s}, 3 \mathrm{H}, \mathrm{CH}_{3}\right)$; ${ }^{13} \mathrm{C}$ NMR $\left(150 \mathrm{MHz}, \mathrm{CDCl}_{3}\right) \delta 193.3,167.5,149.8,149.2$, 144.4, 133.1, 132.2, 129.7, 129.2, 128.9, 122.0, 116.3, 114.1, 110.7, 71.8, 56.0, 51.6. HREIMS $\mathrm{m} / \mathrm{z} 427.0158$ $[\mathrm{M}+\mathrm{Na}]^{+}$(calcd. for $\mathrm{C}_{19} \mathrm{H}_{17} \mathrm{BrNaO}_{5}{ }^{+}, 427.0152$ ).

(E)-Methyl 3-(3-((1-oxo-1-phenylpropan-2-yl)oxy)phenyl) acrylate (8)

Obtained according to the general procedure from 
$0.22 \mathrm{~g}$ (1.22 mmol) of methyl 3-(3-hydroxyphenyl)acrylate, $0.25 \mathrm{~g}(1.20 \mathrm{mmol})$ of 2-bromopropiophenone and $0.30 \mathrm{~g}$ (2.16 mmol) of $\mathrm{K}_{2} \mathrm{CO}_{3}$ and purified by recrystallization from acetone $/ \mathrm{CH}_{2} \mathrm{Cl}_{2}$ (88\% yield). The product obtained was a light yellow crystalline solid (mp $115-117{ }^{\circ} \mathrm{C}$ ). ${ }^{1} \mathrm{H} \mathrm{NMR}\left(600 \mathrm{MHz}, \mathrm{CDCl}_{3}\right) \delta 8.06(\mathrm{~d}, J 7.2 \mathrm{~Hz}, 2 \mathrm{H}, \mathrm{Ar}-\mathrm{H})$, 7.63-7.53 (m, 1H, Ar-H/CH), 7.48 (t, J 7.2 Hz, 2H, Ar-H), 7.24 (t, J 7.8 Hz, 1H, Ar-H), 7.10 (d, J 7.8 Hz, 1H, Ar-H), 7.02 (s, 1H, Ar-H), 6.87 (dd, $\left.J_{1} 7.8 \mathrm{~Hz}, J_{2} 1.8 \mathrm{~Hz}, 1 \mathrm{H}, \mathrm{Ar}-\mathrm{H}\right)$, $6.34(\mathrm{~d}, J 15.6 \mathrm{~Hz}, 1 \mathrm{H}, \mathrm{CH}), 5.50(\mathrm{q}, J 7.2 \mathrm{~Hz}, 1 \mathrm{H}, \mathrm{CH})$, $3.79\left(\mathrm{~s}, 3 \mathrm{H}, \mathrm{OCH}_{3}\right), 1.73\left(\mathrm{~d}, J 7.2 \mathrm{~Hz}, 3 \mathrm{H}, \mathrm{CH}_{3}\right) ;{ }^{13} \mathrm{C} \mathrm{NMR}$ $\left(150 \mathrm{MHz}, \mathrm{CDCl}_{3}\right) \delta 198.5,167.2,157.8,144.4,135.9$, $134.1,133.8,130.0,128.8,128.8,121.3,118.3,116.9$, $114.7,76.7,51.7,18.7$. HREIMS $m / z 333.1099[\mathrm{M}+\mathrm{Na}]^{+}$ (calcd. for $\mathrm{C}_{19} \mathrm{H}_{18} \mathrm{NaO}_{4}{ }^{+}, 333.1098$ ).

\section{2-Oxo-2-phenylethyl-4-(2-oxo-2-phenylethoxy)benzoate (9)}

Obtained according to the general procedure from $0.35 \mathrm{~g}(2.56 \mathrm{mmol}) p$-hydroxybenzoic acid, $0.50 \mathrm{~g}$ $(2.51 \mathrm{mmol})$ of phenacyl bromide and $0.62 \mathrm{~g}(4.52 \mathrm{mmol})$ of $\mathrm{K}_{2} \mathrm{CO}_{3}$ and purified by recrystallization from ethanol ( $41 \%$ yield). The product obtained was a white crystalline solid (mp 146-148 ${ }^{\circ} \mathrm{C}$ ). ${ }^{1} \mathrm{H}$ NMR $\left(500 \mathrm{MHz}, \mathrm{CDCl}_{3}\right) \delta$ 8.07 (d, J $8.9 \mathrm{~Hz}, 2 \mathrm{H}, \mathrm{Ar}-\mathrm{H}), 7.98$ (d, J $8.5 \mathrm{~Hz}, 2 \mathrm{H}, \mathrm{Ar}-\mathrm{H})$, $7.94(\mathrm{~d}, J 8.5 \mathrm{~Hz}, 2 \mathrm{H}, \mathrm{Ar}-\mathrm{H}), 7.46-7.52(\mathrm{~m}, 4 \mathrm{H}, \mathrm{Ar}-\mathrm{H})$, 6.97 (d, J 8.9 Hz, 2H, Ar-H), 5.54 (s, 2H, $\left.\mathrm{CH}_{2}\right), 5.37$ (s, $\left.2 \mathrm{H}, \mathrm{CH}_{2}\right) ;{ }^{13} \mathrm{C}$ NMR (100 MHz, DMSO- $\left.d_{6}\right) \delta$ 193.6, 192.3, 165.5, 162.0, 134.4, 134.3, 134.1, 133.8, 132.1, $128.9,128.9,128.1,127.8,122.7,114.5,70.5,66.3$. HREIMS m/z $397.1052[\mathrm{M}+\mathrm{Na}]^{+}$(calcd. for $\mathrm{C}_{23} \mathrm{H}_{18} \mathrm{NaO}_{5}{ }^{+}$, 397.1047).

\section{Biology}

\section{Cell culture and treatment}

Human myeloid leukemia (KG-1, K-562, HL-60, NB4), human burkit lymphoma (RAMOS, RAJI), human lymphoid T leukemia (JURKAT, CEM, MOLT-4), human lymphoid B leukemia (NALM-6, SUP-B15, RS4;11), human prostatic adenocarcinoma ( $\mathrm{PC} 3, \mathrm{LNCaP})$, human ovarian carcinoma (NCI/ADR), human malignant neoplasm cervix uteri (HeLa), human breast adenocarcinoma (MCF-7), human osteosarcoma (HOS, U-2 0S, MG-63), human glioblastomaastrocytoma, epithelial-like (U-87 MG), human glioblastoma cell lines (U-138 MG) and human non-small cell lung cancer (NCI-H1299) were cultured in RPMI medium supplemented with $10 \%$ fetal calf serum (Gibco 16000-044), $1 \%$ penicillin $\left(10,000 \mathrm{IU} \mathrm{mL}^{-1}\right)$ and streptomycin $10 \mathrm{mg} \mathrm{mL}^{-1}$ $(15,070$ Gibco) and exposed to concentration of drugs $(10 \mu \mathrm{M})$ in DMSO $(0.1 \%)$ and maintained at $37{ }^{\circ} \mathrm{C}$ in $95 \%$ humidified atmosphere, containing $5 \% \mathrm{CO}_{2}$.
In vitro cell viability assay - MTT assay

All steps in this assay were automated in Liquid Handling Workstation epMotion ${ }^{\circledR} 5070$ (Eppendorf, Vaudaux, Schonenbuch, Switzerland). Cells were distributed in 96 wells ( $100 \mu \mathrm{L}$ cells well $\left.{ }^{-1}\right)$ and incubated for $48 \mathrm{~h}$, before addition of test compounds. Cells were then exposed to the compounds at a concentration of $10 \mu \mathrm{M}$. After $24 \mathrm{~h}$ of exposure at $37^{\circ} \mathrm{C}$, cell viability was determined by colorimetric MTT $^{35}$ (3-(4,5-dimethylthiazol2-yl)-2,5-diphenyltetrazoliumbromide) based on the metabolic ability of active cells to convert the yellow MTT reagent into a blue insoluble salt (formazan), which is spectrophotometrically measured. Then, the amount of formazan produced was dissolved in solution containing $150 \mu \mathrm{L}$ of isopropanol and optical density was read by a spectrophotometer at $570 \mathrm{~nm}$ (Bio-Tek Power Wave XS). Absorbance of wells containing the compounds and those with cells in control (cells treated with vehicle, $0.1 \%$ DMSO) were compared to estimate the cell viability. The results were expressed as inhibition percentage relative to control (considered as 100\%) and doxorubicin was used as a reference drug. Compound $\mathbf{6 c}$ was also evaluated for cytotoxicity against human leukemia cells, using the MTT method. Doxorubicin was used as positive control. All assays were performed in triplicate and mean \pm standard deviation (SD) values were used to estimate cell viability.

\section{Results and Discussion}

\section{Chemistry}

In this work, 25 oxyneolignan analogues ( $\beta$-ketoethers or $\beta$-ketoesters) were synthesized and the synthetic strategies for their preparation are summarized in Scheme 1 . The $\beta$-ketoethers and $\beta$-ketoesters analogues 3a-3j, 4a-4c, 5a-5b, 6a-6f, 7a-7b, 8 and 9 (Table 1) were obtained following a procedure described by Barata $\mathrm{et} \mathrm{al.}{ }^{26}$

Initially, the $\alpha$-bromoketone intermediates $\mathbf{2 a - 2 b}$ were prepared according to a known procedure, ${ }^{26}$ then, without any purification due to their lacrimogenic property, were reacted with an in situ generated phenoxy and/or carboxylate ion. These condensation reactions were carried out in the presence of $\mathrm{K}_{2} \mathrm{CO}_{3}$ and butanone as solvent furnishing the products in yields ranging from 40 to $100 \%$. The phenolic/carboxylic compounds were used in an excess of $2 \%$ instead of using excess of $\alpha$-bromoketone. During isolation, the volume of solvent was reduced to $1 / 3$ of the initial volume before work-up, since the slight solubility of the solvents in water hampers the isolation procedure.

In order to obtain compounds $\mathbf{7} \mathbf{a}-\mathbf{7 b}$ and $\mathbf{8}$, previous esterification of the cinnamic acid derivatives with 


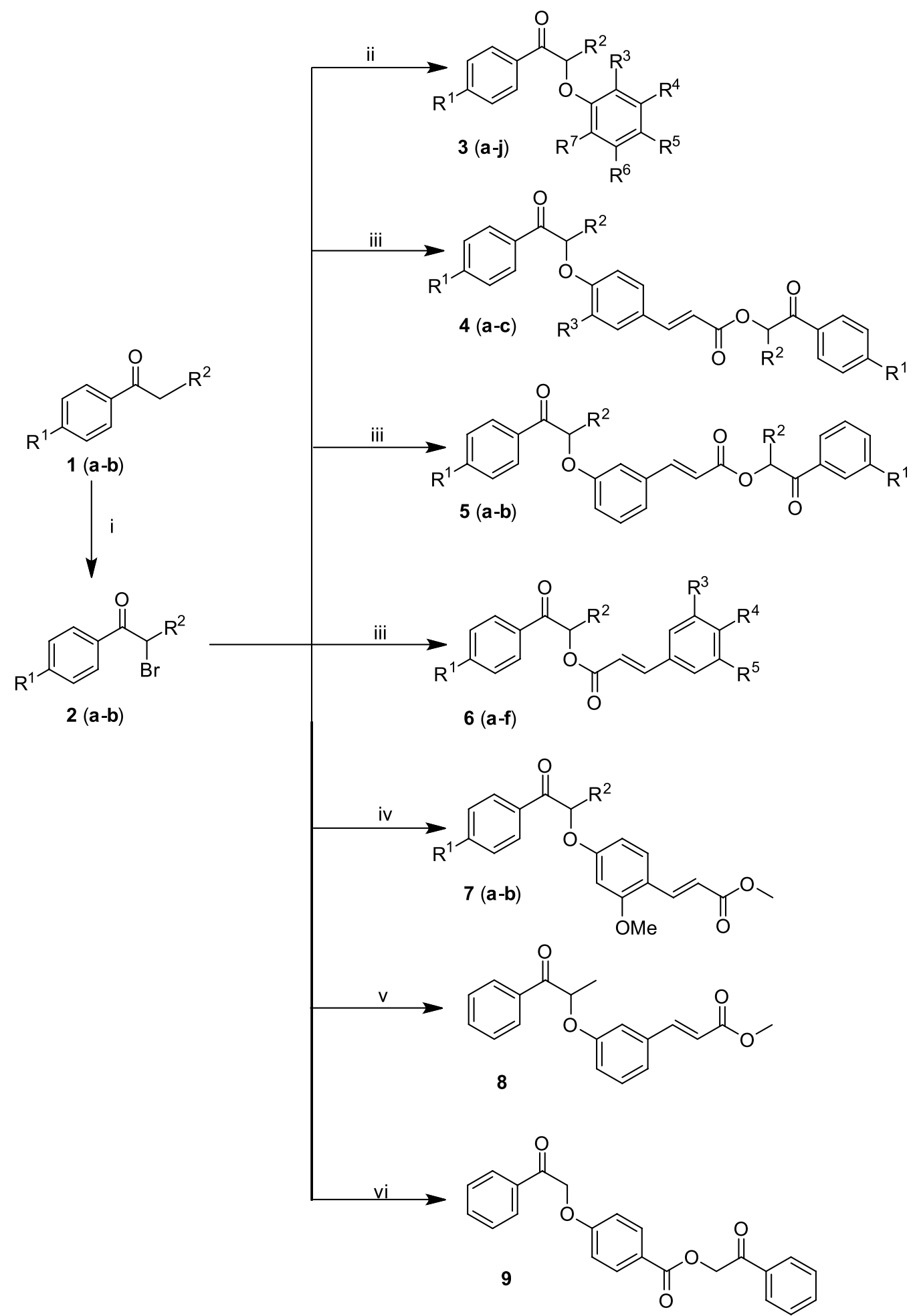

Scheme 1. Synthesis of 8,4'-oxyneolignan analogues. Reagents and conditions: (i) $\mathrm{Br}_{2}, \mathrm{CHCl}_{3}$ r.t. $2 \mathrm{~h}$; (ii) $\mathrm{ArOH}, \mathrm{K}_{2} \mathrm{CO}_{3}$, butanone or $\mathrm{MeCN}^{\circ} 80^{\circ} \mathrm{C}, 12 \mathrm{~h}$; (iii) cinnamic acids, $\mathrm{K}_{2} \mathrm{CO}_{3}$, butanone or $\mathrm{MeCN}, 80^{\circ} \mathrm{C}$; (iv) methyl ferulate, butanone or $\mathrm{MeCN}, 80{ }^{\circ} \mathrm{C}, 12 \mathrm{~h}$; (v) methyl 3-hydroxycinnamate, $\mathrm{K}_{2} \mathrm{CO}_{3}$, butanone or $\mathrm{MeCN}, 80^{\circ} \mathrm{C}$; (vi) 4-hydroxy-benzoic acid, $\mathrm{K}_{2} \mathrm{CO}_{3}$, butanone, $80{ }^{\circ} \mathrm{C}$.

methanol and sulfuric acid was mandatory to avoid the competitive nucleophilic displacement of the bromine atom by the carboxylate anions. This was confirmed in the obtention of compounds $\mathbf{4 a - 4}$ and $\mathbf{5 a - 5} \mathbf{b}$ by using
2 equivalents of $\mathbf{2} \mathbf{a}-\mathbf{2} \mathbf{b}$. As far as we know, this creates a new subclass of 8,4'-oxyneolignan analogues, which we called 8,4'-oxyneolignan cinnamic analogues. Compound 9 was synthesized in a similar fashion. 
Table 1. Chemical structures, yields, and melting points (mp) of the synthesized compounds

\begin{tabular}{|c|c|c|c|}
\hline Compound & Structure & Yield / \% & $\mathrm{mp} /{ }^{\circ} \mathrm{C}$ \\
\hline $3 \mathbf{a}$ & & 84 & $148-150$ \\
\hline $3 \mathbf{b}$ & & 42 & $74-75$ \\
\hline $3 c$ & & 91 & $78-80$ \\
\hline 3d & & 100 & $125-127$ \\
\hline $3 e$ & & 69 & $70-72$ \\
\hline $3 f$ & & 54 & - \\
\hline $3 \mathbf{g}$ & & 66 & $111-112$ \\
\hline $3 \mathbf{h}$ & & 54 & $109-111$ \\
\hline $3 \mathbf{i}$ & & 39 & $99-101$ \\
\hline
\end{tabular}


Vol. 28, No. 11, 2017

Souza et al.

2237

Table 1. Chemical structures, yields, and melting points (mp) of the synthesized compounds (cont.)

Compound

jj

$4 a$

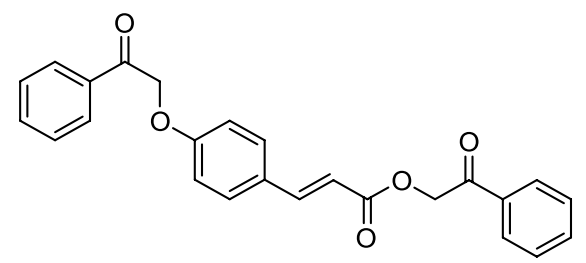

$4 b$

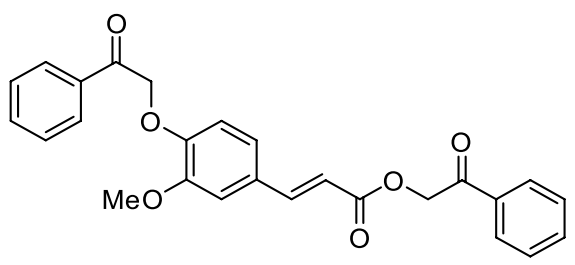

Ac<smiles>COc1ccc(C(=O)C(C)OC(=O)/C=C/c2ccc(OC(C)C(=O)c3ccc(OC)cc3)cc2)cc1</smiles>

$5 \mathbf{a}$

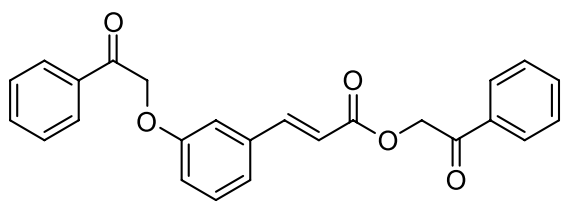

$5 b$

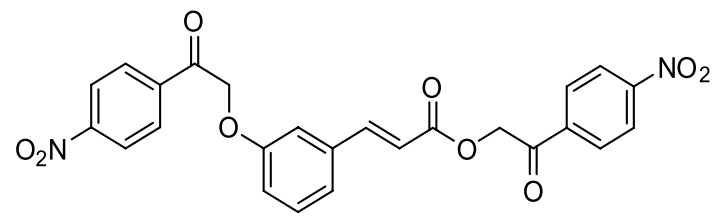

$6 a$

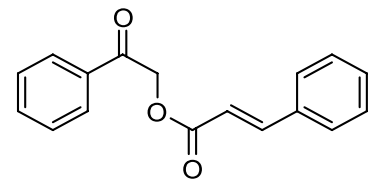

Gb

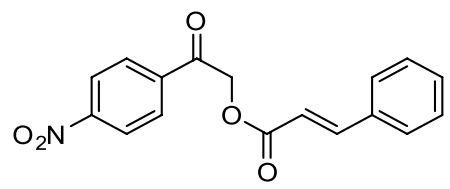<smiles>CC(OC(=O)/C=C/c1ccccc1)C(=O)c1ccccc1</smiles>

Yield / \%

$\mathrm{mp} /{ }^{\circ} \mathrm{C}$

69

91-93

55

145-147

74

135-137

71

142-144

76

139-141

45

101-103

86

141-143

75

157-158

57

70-71 
Table 1. Chemical structures, yields, and melting points (mp) of the synthesized compounds (cont.)

\begin{tabular}{|c|c|c|c|}
\hline Compound & Structure & Yield $/ \%$ & $\mathrm{mp} /{ }^{\circ} \mathrm{C}$ \\
\hline 6d & & 59 & $128-130$ \\
\hline $6 e$ & & 69 & $144-146$ \\
\hline 6f & & 45 & $117-119$ \\
\hline $7 a$ & & 53 & $105-107$ \\
\hline 7b & & 68 & $160-162$ \\
\hline 8 & & 88 & $115-117$ \\
\hline 9 & & 41 & $146-148$ \\
\hline
\end{tabular}

The ${ }^{1} \mathrm{H}$ NMR spectra of the products show the presence of one peak (compounds $\mathbf{3}, \mathbf{6 , 7}$ and $\mathbf{8}$ ) or two peaks (compounds $\mathbf{4}, \mathbf{5}$ and $\mathbf{9}$ ) in between 5.12-6.14 ppm, assignable to the $\mathrm{CH}_{2} / \mathrm{CH}$ carbinolic protons. These signals confirm the formation of the $\mathrm{C}-\mathrm{O}-\mathrm{C}$ bond and, consequently, the expected products.

All synthesized substances were purified by crystallization and fully characterized by usual spectroscopic methods (melting points, HRMS, ${ }^{1} \mathrm{H}$ and ${ }^{13} \mathrm{C} \mathrm{NMR}$ ). The chemical structures are described in Table 1.

\section{Biology}

To evaluate the antiproliferative activity, the amount of surviving cells at the dose level of $10 \mu \mathrm{M}$ was measured after $24 \mathrm{~h}$ of incubation by the MTT method colorimetric assay ${ }^{35}$ and the results were expressed as percentage of inhibition relative to control and compared with the reference drug (doxorubicin). The tests were carried out in triplicate, using doxorubicin as positive control and these data are schematically listed in Table 2. 
Table 2. Evaluation of cytotoxicity towards leukemia cells (\% inhibition) ${ }^{\mathrm{a}}$ for all synthesized compounds

\begin{tabular}{|c|c|c|c|c|c|}
\hline entry & Compound & K-562 & HL-60 & Nalm-6 & Ramos \\
\hline 1 & $3 a$ & 11.8 & 15.4 & $<5$ & 14.7 \\
\hline 2 & $\mathbf{3 b}$ & 15.6 & 4.8 & 5.8 & 21.0 \\
\hline 3 & $3 c$ & 20.4 & 10.9 & 8.7 & $<5$ \\
\hline 4 & 3d & 28.3 & 26.1 & 13.4 & 29.8 \\
\hline 5 & $3 e$ & NT & NT & NT & NT \\
\hline 6 & $3 f$ & 17.2 & 1.4 & $<5$ & 15.0 \\
\hline 7 & $3 g$ & 34.4 & 6.5 & $<5$ & 18.6 \\
\hline 8 & $3 \mathrm{~h}$ & 13.9 & 16.9 & $<5$ & 10.4 \\
\hline 9 & $3 \mathbf{i}$ & 10.3 & 8.7 & 14.1 & 18.5 \\
\hline 10 & $3 \mathbf{j}$ & 27.4 & 38.1 & $<5$ & 17.6 \\
\hline 11 & $4 a$ & 34.1 & 52.1 & 56.7 & 48.6 \\
\hline 12 & $4 b$ & $<10$ & 57.5 & 62.0 & 60.4 \\
\hline 13 & $4 c$ & NT & NT & NT & NT \\
\hline 14 & $5 a$ & 21.6 & $<5$ & 12.4 & 17.9 \\
\hline 15 & $5 \mathbf{b}$ & 12.2 & $<5$ & 8.6 & 15.7 \\
\hline 16 & $6 a$ & 39.3 & 34.1 & 32.6 & 43.7 \\
\hline 17 & $6 b$ & 27.8 & 7.1 & 21.7 & 42.8 \\
\hline 18 & $6 c$ & 52.2 & 86.3 & 73.2 & 84.6 \\
\hline 19 & 6d & $<5$ & 51.4 & 56.9 & 61.3 \\
\hline 20 & $6 e$ & 43.6 & 33.2 & 38.5 & 38.3 \\
\hline 21 & $6 f$ & 19.9 & 33.7 & 34.9 & 36.9 \\
\hline 22 & $7 a$ & NT & NT & NT & NT \\
\hline 23 & $7 b$ & 13.7 & 16.3 & $<5$ & 9.9 \\
\hline 24 & 8 & 12.8 & 14.8 & 9.9 & 21.7 \\
\hline 25 & 9 & 47.0 & 66.7 & 51.6 & 54.1 \\
\hline 26 & doxorubicin & 71.1 & 97.7 & 65.4 & 81.3 \\
\hline
\end{tabular}

${ }^{a}$ Inhibition percentages measured at a single concentration of $10 \mu \mathrm{M}$. NT: not tested.

The antiproliferative screening results show that five compounds presented a promising antiproliferative activity ( $\geq 50 \%$ of cell inhibition) against the leukemia cell lines. The other analogues were less active or completely inactive at the dose of $10 \mu \mathrm{M}$. Compounds $4 \mathbf{a}, \mathbf{4 b}, \mathbf{6 d}$ and 9 (entries 11, 12, 19 and 25, respectively) demonstrate similar inhibition of growth proliferation against HL-60, Ramos and Nalm-6 (48.6-66.7\%). The same substances did not reveal a good inhibition level against K-562 cells. The best compound of the series was $\mathbf{6 c}$ (entry 18) inhibiting cell proliferation over $50 \%$ against four leukemia cell lines and very comparable to the positive control used in this test (entry 26). For Nalm-6 and Ramos cells, the percentage of inhibition was even superior to doxorubicin inhibition, presenting 73.2 and $84.6 \%$, respectively.

Compounds which presented significant activity profile against leukemia cells $(\mathbf{4 a}, \mathbf{4 b}, \mathbf{6 c}, \mathbf{6 d}, \mathbf{9})$ were selected to be evaluated for their activity on cell proliferation on other nineteen different kinds of human neoplasms, among tumors and leukemia cell lines. These tests were performed by using the MTT method, as previously mentioned. The cells used in this evaluation are listed in the Experimental section and the obtained results are shown on Tables 3-4 and Figures 1-2.

Table 3. Evaluation of antiproliferative activity towards tumor cells (\% inhibition at $10 \mu \mathrm{M}$ ) for compounds $4 \mathbf{a}, 4 \mathbf{b}, \mathbf{6 c}, \mathbf{6 d}$ and $\mathbf{9}$

\begin{tabular}{lcccccc}
\hline \multirow{2}{*}{ Tumor } & \multicolumn{6}{c}{ Antiproliferative activity / $(\%$ inhibition at $10 \mu \mathrm{M})$} \\
\cline { 2 - 7 } & $\mathbf{4 a}$ & $\mathbf{4 b}$ & $\mathbf{6 c}$ & $\mathbf{6 d}$ & $\mathbf{9}$ & Doxorubicin \\
\hline PC3 & 82.9 & 67.3 & 57.1 & 47.1 & 47.5 & 85.1 \\
LNCaP & 64.3 & 67.6 & 74.9 & 50.6 & 50.0 & 86.0 \\
NCI/ADR & 76.2 & 56.5 & 60.1 & 42.6 & 58.4 & 94.0 \\
MCF-7 & 39.7 & 35.2 & 59.0 & 31.2 & 36.5 & 72.1 \\
HeLa & 61.3 & 71.1 & 36.3 & 51.4 & 33.7 & 93.7 \\
U-87 & 72.2 & 34.2 & 43.4 & 32.1 & 50.0 & 59.0 \\
U-138 MG & 75.7 & 5.4 & 29.8 & 27.0 & 53.0 & 73.2 \\
HOS & 76.3 & 66.6 & 68.3 & 65.0 & 27.5 & 91.5 \\
U-2 OS & 21.2 & 52.0 & 41.9 & 35.2 & 20.9 & 90.5 \\
MG-63 & 71.7 & 59.4 & 70.2 & 36.9 & 54.0 & 74.5 \\
H1299 & 73.4 & 24.8 & 15.0 & 23.1 & 35.5 & 65.4 \\
\hline
\end{tabular}

Table 4. Evaluation of cytotoxicity towards leukemia cells (\% inhibition at $10 \mu \mathrm{M}$ ) for compounds $\mathbf{4 a}, \mathbf{4 b}, \mathbf{6 c}, \mathbf{6 d}$ and $\mathbf{9}$

\begin{tabular}{lcccccc}
\hline \multirow{2}{*}{$\begin{array}{l}\text { Leukemia } \\
\text { cell }\end{array}$} & \multicolumn{6}{c}{ Cytotoxicity / $(\%$ inhibition at $10 \mu \mathrm{M})$} \\
\cline { 2 - 7 } & $\mathbf{4 a}$ & $\mathbf{4 b}$ & $\mathbf{6 c}$ & $\mathbf{6 d}$ & $\mathbf{9}$ & Doxorubicin \\
\hline KG-1 & 55.1 & 92.0 & 89.7 & 34.0 & $<5$ & 86.9 \\
NB4 & 33.2 & 48.9 & 81.4 & 35.2 & 45.0 & 88.2 \\
RAJI & 19.6 & 37.9 & 65.5 & 46.3 & 37.1 & 90.8 \\
JURKAT & 56.8 & 62.2 & 91.2 & 51.9 & 40.8 & 97.5 \\
CEM & 52.4 & 61.7 & 91.1 & 45.6 & 57.8 & 98.4 \\
MOLT-4 & 14.1 & 41.5 & 87.1 & 34.0 & 62.0 & 90.0 \\
SUP-B15 & 48.5 & 57.4 & 64.4 & 51.7 & 56.4 & 89.4 \\
RS4;11 & 53.0 & 40.5 & 89.6 & 35.8 & 50.5 & 95.2 \\
\hline
\end{tabular}

As can be seen from Table 3 and Figures 1-2, all compounds exhibited some degree of activity against the eleven tumor cells used in this assay. $\beta$-Ketoester $\mathbf{6 c}$ presented a good antiproliferative activity for tumors, specially LNCaP (74.9\%), HOS (68.3\%) and MG-63 (70.2\%), whereas compound $\mathbf{6 d}$ showed an inhibition rate greater than $50 \%$ only for LNCaP (50.6\%), HeLa (51.4\%) and HOS $(65.0 \%)$ tumors. The oxyneolignan analogue 9 demonstrated a considerable reduction of cell growth on four tumor cells: LNCaP (50.0\%), NCI/ADR (58.4\%), U-138 MG (53.0\%) and MG-63 (54.0\%). 


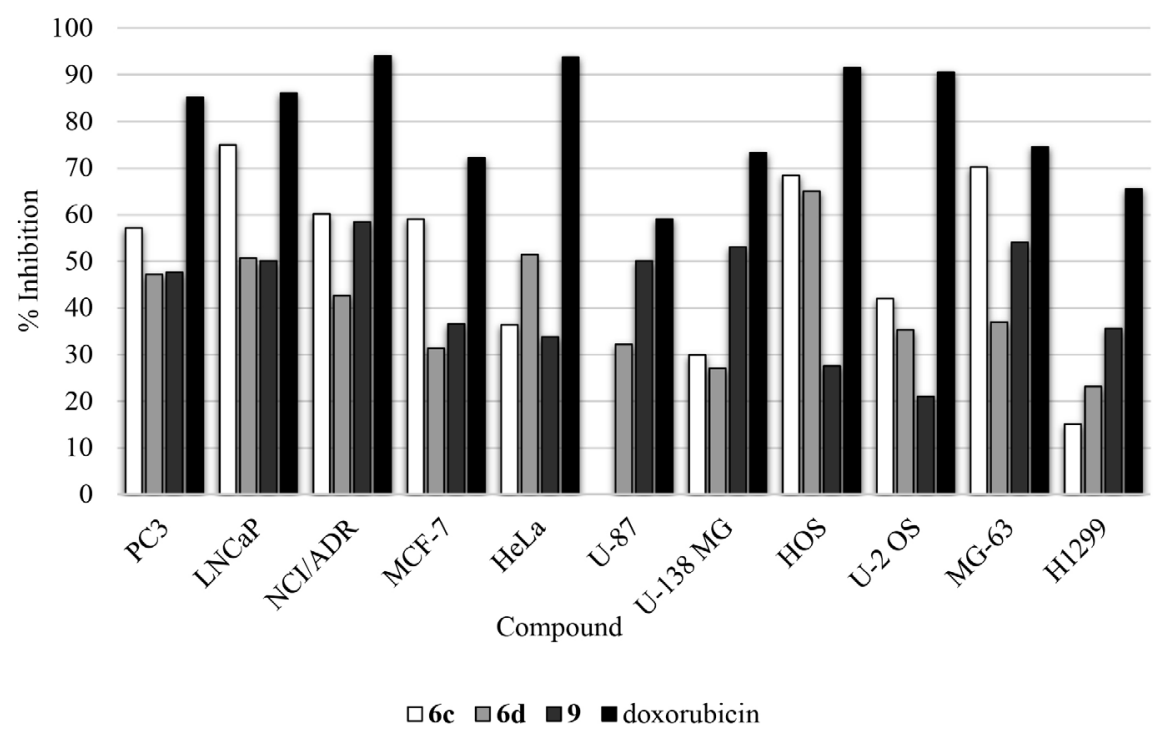

Figure 1. MTT assay for human tumor cell lines of compounds $\mathbf{6 c}, \mathbf{6 d}$ and $\mathbf{9}$.

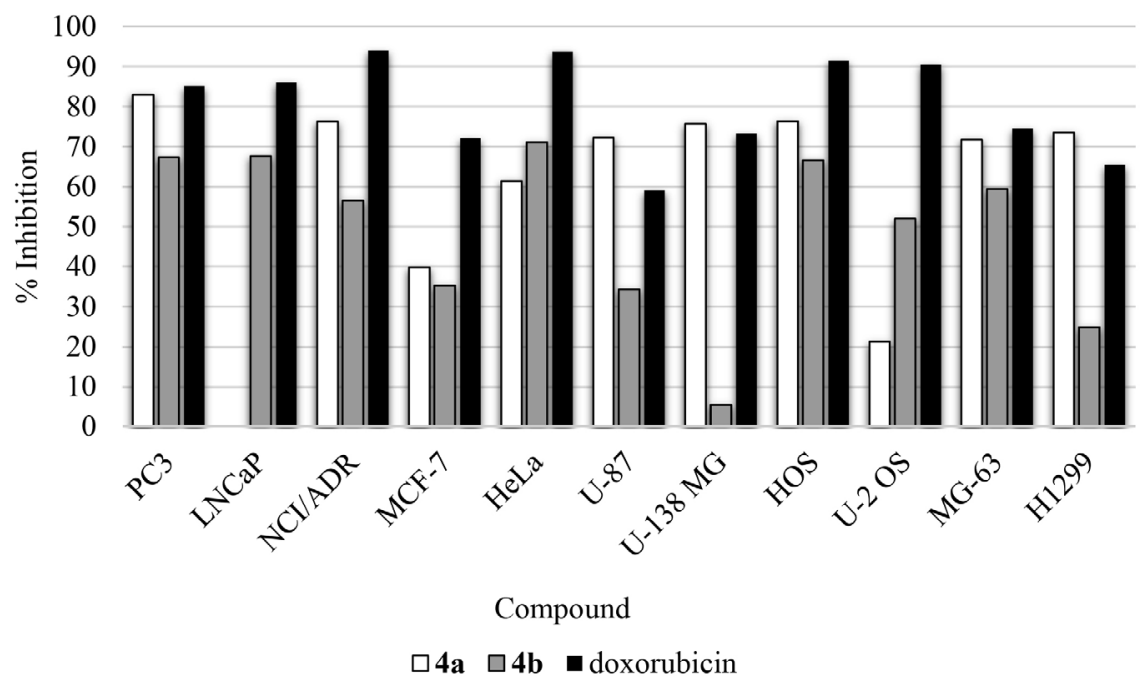

Figure 2. MTT assay for human tumor cell lines of compounds $\mathbf{4 a}$ and $\mathbf{4 b}$.

8,4'-Oxyneolignan cinnamic analogues $\mathbf{4 a}$ and $\mathbf{4 b}$ were shown to be active against most cells, exhibiting a good inhibition profile. The most active compound was $\mathbf{4 a}$, showing a significant inhibition rate of cell growth against PC3 (82.9\%), MG-63 (71.7\%), U-87 (72.2\%), U-138 MG (75.7\%) and H1299 (73.4\%) tumors. In these last three cell lines results, the activity of the oxyneolignan 4 a was even superior to that of doxorubicin, the positive control used in this trial.

The evaluation of compounds $\mathbf{4 a}, \mathbf{4 b}, \mathbf{6 c}, \mathbf{6 d}$ and 9 on leukemic cells are expressed in Table 4 and Figures 3-4.

Compound 9 was most active against CEM, SUP-B15, MOLT-4 and RS4; 11 cells, reducing its growth by 50.5 to $62.0 \%$. Compound $4 \mathrm{a}$ presented levels of cell inhibition against KG-1, JUKART, CEM, RS4;11 around 52.4-56.8\%, whereas a great selectivity and stronger antiproliferative activity were observed for compound $\mathbf{4 b}$, which exhibited $92.0 \%$ of inhibition against KG-1 cells.

Compound $\mathbf{6} \mathbf{c}$ was found to be the most promising of the series, presenting antileukemic activity higher than $50 \%$ for all cell lines used in this study and superior or comparable results when compared to the reference drug. In the case of KG-1 cells, the extent of inhibition levels of products $\mathbf{4 b}$ and $\mathbf{6 c}$ were even better than doxorubicin, indicating its possible efficacy against this leukemia type.

Considering the results obtained in the antiproliferative tests (Table 4, Figure 4), in vitro cytotoxicity assay was used to assess the activity of the most potent compound (6c). The analogue was tested against eleven human leukemic cell lines. The assays were carried out in triplicate, and doxorubicin was used as the positive control. The biological endpoint was determined according to the concentration, 


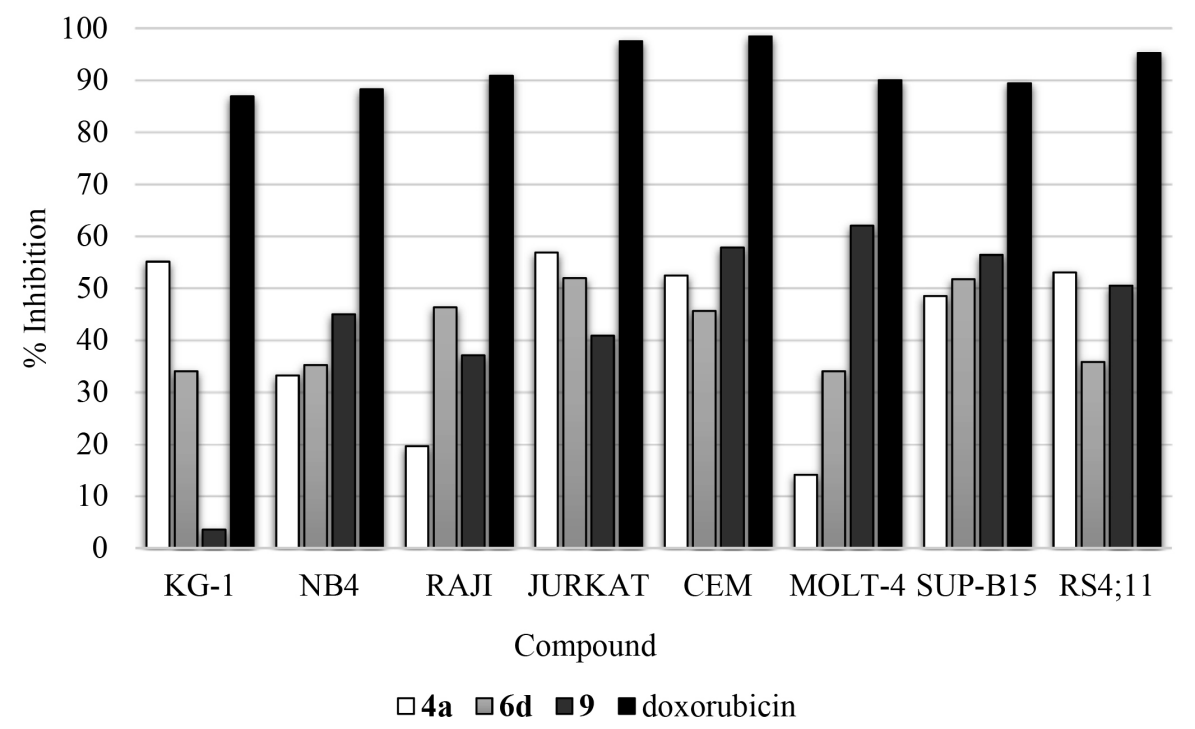

Figure 3. MTT assay for human leukemia cell lines of compounds $\mathbf{4 a}, \mathbf{6 d}$ and $\mathbf{9 .}$

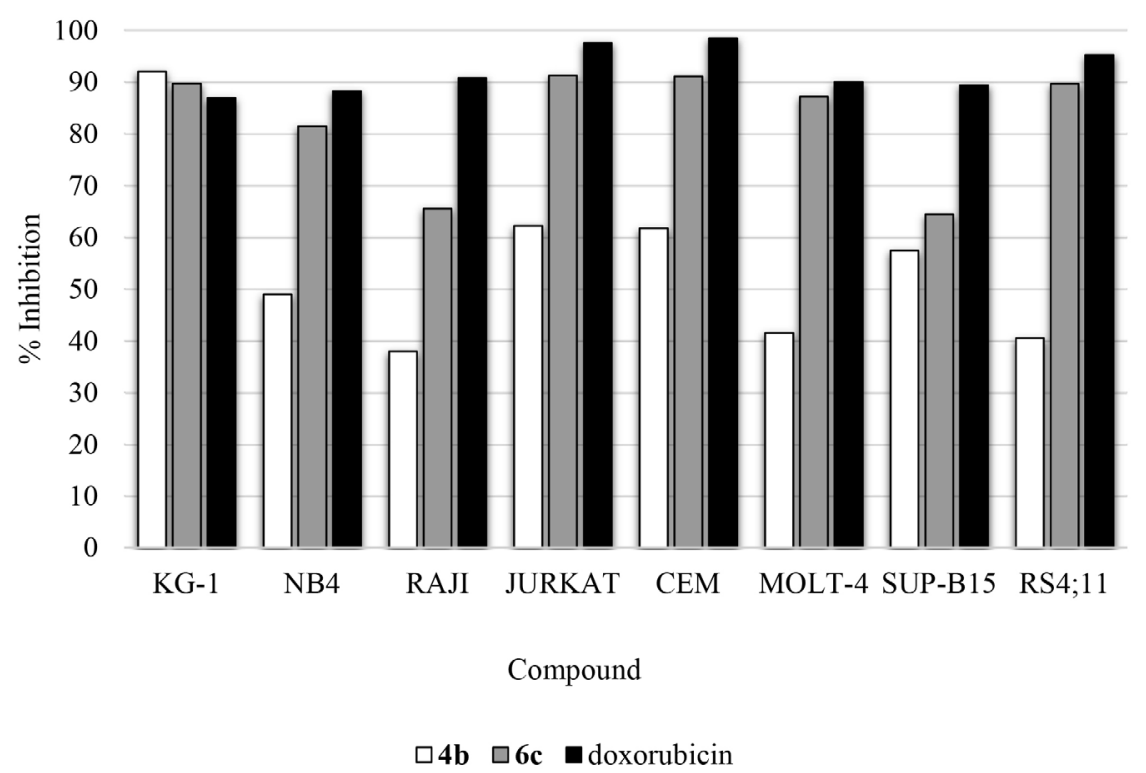

Figure 4. MTT assay for human leukemia cell lines of compounds $\mathbf{4 b}$ and $\mathbf{6 c}$.

which causes fifty percent of cell growth inhibition $\left(\mathrm{IC}_{50}\right)$. Compound $\mathbf{6 c}$ showed similar values of $\mathrm{IC}_{50}$ against leukemia cells (Table 5), ranging from moderate to good activity, except for K-562 cells, for which the drug showed no activity. Compound $\mathbf{6 c}$ induced better cytotoxic effects on Ramos cells, which presented an $\mathrm{IC}_{50}$ of $9.4 \mu \mathrm{M}$.

The correlation between the structures of the synthesized compounds and their antiproliferative activities leads to the conclusion that the compounds bearing a cinnamic moiety on its structure possess better potency in MTT assay. The presence of the cinnamic portion in the basic structure of the 8,4'-oxyneolignans and the variation on its position on the aromatic ring affect considerably the antiproliferative activities. When comparing compounds $\mathbf{4 a}-\mathbf{4} \mathbf{b}$ and $\mathbf{5 a} \mathbf{a}-\mathbf{5 b}$, 7a-7b and 8 better inhibition showed by compounds $4 a$ and $4 \mathrm{~b}$ against cancer cells could be attributed to its para substitution, whereas meta-substituted compounds $\mathbf{5 a - 5 b}$ did not show an expressive percentage of inhibition. However, in compounds $\mathbf{7 a - 7 b}$ and $\mathbf{8}$, the cinnamate moiety and the absence of an aromatic ring may be responsible for the drastic decrease in activity.

In the 8,4'-oxyneolignans $\mathbf{3 a - 3} \mathbf{j}$, the effects of substitution on the aromatic rings were not clearly observed. These compounds did not show enhanced activity when comparing substituent groups, positions and side chain length.

Among compounds 6a-6f, as shown in Tables 2 and 3, the effect of alkyl chain substitution in compound $\mathbf{6 c}$ greatly 
Table 5. In vitro cytotoxicity of compound $\mathbf{6 c}$ against leukemia cell lines

\begin{tabular}{lcc}
\hline Leukemia cell & Doxorubicin $\mathrm{IC}_{50} / \mu \mathrm{M}$ & $\mathbf{6 c ~}^{\mathrm{IC}_{50}} / \mu \mathrm{M}$ \\
\hline K-562 & 3.1 & $>100$ \\
KG-1 & 0.8 & 12.0 \\
HL-60 & 0.5 & 12.6 \\
NB4 & 0.4 & 12.6 \\
Ramos & 5.7 & 9.4 \\
RAJI & 1.0 & 18.5 \\
Nalm-6 & 0.2 & 13.5 \\
JURKAT & 0.5 & 14.2 \\
MOLT-4 & 0.1 & 14.0 \\
SUP-B15 & 0.5 & 33.7 \\
RS4;11 & 0.1 & 13.3 \\
CEM & $\mathrm{NT}$ & $\mathrm{NT}$ \\
\hline
\end{tabular}

Incubation time $=24 \mathrm{~h} ; \mathrm{IC}_{50}>100 \mu \mathrm{M}$ means not active; NT: not tested.

decreased cell proliferation when compared to compound 6a. In the same aspect, the presence of a halogen substituent in compound $\mathbf{6 d}$ intensified the cytotoxicity level compared to $\mathbf{6 a}$ and also compared with $\mathbf{6} \mathbf{b}$, which possesses an electron-withdrawing group at the same position. These results suggest that the electronic characteristics of the substituent groups and the alkyl chain affect the capability of the molecule to interact with the bioactive target increasing/ decreasing the antiproliferative activity.

\section{Conclusions}

From our study we were able to produce a new subclass of neolignan analogues, the 8,4'-oxyneolignan cinnamic analogues. These compounds were evaluated against a variety of cancer cell lines, among tumors and leukemias. In tumor cells assays we identified that compound $\mathbf{4 a}$ showed an antiproliferative activity superior to doxorubicin for U-87, U-138 MG and H1299 cell types. Compound 6c exhibited significant inhibition activity in a range of 52.2 to $91.2 \%$ against twelve kinds of leukemia cell lines, revealing excellent results and very comparable to the reference drug. In addition, compound $\mathbf{4 b}$ was found to be very selective, demonstrating a growth inhibition of $92.0 \%$ against KG-1 cells. These preliminary results suggest that further investigation is needed to elucidate the characteristics underlying the antiproliferative activities of these analogues.

\section{Supplementary Information}

The supplementary data of ${ }^{1} \mathrm{H}$ NMR, ${ }^{13} \mathrm{C}$ NMR and HRMS spectra of all compounds synthesized are available free of charge at http://jbcs.org.br as a PDF file.

\section{Acknowledgments}

The authors gratefully acknowledge National Council for Scientific and Technological Development (CNPq) and University of Brasilia (UnB) for financial support.

\section{References}

1. World Health Organization, WHO Cancer Factsheet No. 297, updated February 2017. Available at http://www.who.int/ mediacentre/factsheets/fs297/en/, accessed in April 2017.

2. American Cancer Society, Cancer Facts \& Figures 2016. Available at: http://www.cancer.org/acs/groups/content/@ research/documents/document/acspc-047079.pdf, accessed in April 2017.

3. Sawyers, C.; Nature 2004, 432, 294.

4. Twelves, C.; Jove, M.; Gombos, A.; Awada, A.; Crit. Rev. Oncol. Hematol. 2016, 100, 74.

5. Jimeno, A.; Hidalgo, M.; Crit. Rev. Oncol. Hematol. 2006, 59 , 150.

6. Gottlieb, O. R.; Phytochemistry 1972, 11, 1537.

7. Barata, L. E. S.; Baker, P. M.; Gottlieb, O. R.; Rùveda, E. A.; Phytochemistry 1978, 17, 783.

8. Vassão, D. G.; Kim, K. W.; Davin, L. B.; Lewis, N. G.; Comprehensive Natural Products II: Chemistry and Biology, vol. 1; Mander, L.; Liu, H.-W., eds.; Elsevier: Oxford, 2010, p. 815.

9. Mollataghi, A.; Hadi, A. H. M.; Awang, K.; Mohamad, J.; Litaudon, M.; Mukhtar, M. R.; Molecules 2011, 16, 6582.

10. Ribeiro, A. B.; Bolzani, V. D. S.; Yoshida, M.; Santos, L. S.; Eberlin, M. N.; Silva, D. H. S.; J. Braz. Chem. Soc. 2005, 16, 526.

11. Lee, W. S.; Baek, Y.; Kim, J. R.; Cho, K. H.; Sok, D. E.; Jeong, T. S.; Bioorg. Med. Chem. Lett. 2004, 14, 5623.

12. Salleh, W. M. N. H. W.; Ahmad, F.; Yen, K. H.; Zulkifli, R. M.; Sarker, S. D.; Phytochem. Lett. 2016, 15, 168.

13. Huang, X. X.; Zhou, C. C.; Li, L. Z.; Peng, Y.; Lou, L. L.; Liu, S.; Li, D. M.; Ikejima, T.; Song, S. J.; Fitoterapia 2013, 91, 217.

14. Syu, W. J.; Shen, C. C.; Lu, J. J.; Lee, G. H.; Sun, C. M.; Chem. Biodiversity 2004, 1, 530.

15. Scodro, R. B. L.; Pires, C. T. A.; Carrara, V. S.; Lemos, C. O. T.; Cardozo-Filho, L.; Souza, V. A.; Corrêa, A. G.; Siqueira, V. L. D.; Lonardoni, M. V. C.; Cardoso, R. F.; Cortez, D. A. G.; Phytomedicine 2013, 20, 600.

16. Chen, S.; Huang, H. Y.; Cheng, M. J.; Wu, C. C.; Ishikawa, T.; Peng, C. F.; Chang, H. S.; Wang, C. J.; Wong, S. L.; Chen, I. S.; Phytochemistry 2013, 93, 203.

17. León-Díaz, R.; Meckes-Fischer, M.; Valdovinos-Martínez, L.; Campos, M. G.; Hernández-Pando, R.; Jiménez-Arellanes, M. A.; Arch. Med. Res. 2013, 44, 99.

18. Shih, H. C.; Kuo, P. C.; Wu, S. J.; Hwang, T. L.; Hung, H. Y.; Shen, D. Y.; Shieh, P. C.; Liao, Y. R.; Lee, E. J.; Gu, Q.; Lee, K. H.; Wu, T. S.; Bioorg. Med. Chem. 2016, 24, 1439. 
19. Kuo, W. L.; Chung, C. Y.; Hwang, T. L.; Chen, J. J.; Phytochemistry 2013, 85, 153.

20. Oh, J. H.; Kang, L. L.; Ban, J. O.; Kim, Y. H.; Kim, K. H.; Han, S. B.; Hong, J. T.; Chem. Biol. Interact. 2009, 180, 506.

21. Tzeng, S. C.; Liu, Y. C.; J. Mol. Catal. B: Enzym. 2004, $32,7$.

22. Koroishi, A. M.; Foss, S. R.; Cortez, D. A. G.; Ueda-Nakamura, T.; Nakamura, C. V.; Dias Filho, B. P.; J. Ethnopharmacol. 2008, 117,270

23. Pinheiro, A. A. C.; Borges, R. S.; Santos, L. S.; Alves, C. N.; J. Mol. Struct.: THEOCHEM 2004, 672, 215.

24. Néris, P. L. N.; Caldas, J. P. A.; Rodrigues, Y. K. S.; Amorim, F. M.; Leite, J. A.; Rodrigues-Mascarenhas, S.; Barbosa-Filho, J. M.; Rodrigues, L. C.; Oliveira, M. R.; Exp. Parasitol. 2013, $135,307$.

25. Aveniente, M.; Pinto, E. F.; Santos, L. S.; Rossi-Bergmann, B.; Barata, L. E. S.; Bioorg. Med. Chem. 2007, 15, 7337.

26. Barata, L. E. S.; Santos, L. S.; Ferri, P. H.; Phillipson, J. D.; Paine, A.; Croft, S. L.; Phytochemistry 2000, 55, 589.

27. Cassamale, T. B.; Costa, E. C.; Carvalho, D. B.; Cassemiro, N. S.; Tomazela, C. C.; Marques, M. C. S.; Ojeda, M.; Matos, M. F. C.; Albuquerque, S.; Arruda, C. C. P.; Baroni, A. C. M.; J. Braz. Chem. Soc. 2016, 27, 1217.
28. Cabral, M. M. O.; Barbosa-Filho, J. M.; Maia, G. L. A.; Chaves, M. C. O.; Braga, M. V.; de Souza, W.; Soares, R. O. A.; Exp. Parasitol. 2010, 124, 319.

29. Acuña, U.; Carcache, P. J. B.; Matthew, S.; Carcache De Blanco, E. J.; Food Chem. 2016, 202, 269.

30. Ponci, V.; Figueiredo, C. R.; Massaoka, M. H.; de Farias, C. F.; Matsuo, A. L.; Sartorelli, P.; Lago, J. H. G.; Molecules 2015, 20, 12757.

31. Amblard, F.; Govindarajan, B.; Lefkove, B.; Rapp, K. L.; Detorio, M.; Arbiser, J. L.; Schinazi, R. F.; Bioorg. Med. Chem. Lett. 2007, 17, 4428.

32. Moriyama, M.; Huang, J. M.; Yang, C. S.; Hioki, H.; Kubo, M.; Harada, K.; Fukuyama, Y.; Tetrahedron 2007, 63, 4243.

33. Yang, E. J.; Lee, J. Y.; Park, S. H.; Lee, T.; Song, K. S.; Food Chem. Toxicol. 2013, 56, 304.

34. Kim, K. H.; Choi, J. W.; Ha, S. K.; Kim, S. Y.; Lee, K. R.; Bioorg. Med. Chem. Lett. 2010, 20, 409.

35. Mosmann, T.; J. Immunol. Methods 1983, 65, 55.

Submitted: February 17, 2017

Published online: April 26, 2017 